\title{
El problema de las raíces asiáticas del primer poblamiento de América
}

\author{
Janusz K. Kozlowski y Hans-Georg Band
}

La finalidad de este estudio * es, por una parte, el reexaminar el problema del origen del poblamiento de América en la perspectiva del avance reciente de las investigaciones arqueológicas en el nordeste de Asia y en Alaska y, por otra parte, el recordar ciertos aspectos de la evolución cultural, tanto en Asia como en América, durante la última glaciación. Se puede considerar este estudio como una contribución a la discusión sostenida en los años setenta en diversos fasciculos de la publicación norteamericana Quaternary Research (BRYAN 1973, LYNCH 1974, RousE 1976) referentes a las diferentes opiniones acerca de las etapas iniciales del desarrollo cultural del Nuevo Mundo. Hemos querido romper con un cierto eurocentrismo en el estudio del Paleolítico de Asia y de América que se habia puesto de manifiesto en la búsqueda de raices europeas para las civilizaciones del Asia oriental y por consiguiente de América. Es necesario restituir sus proporciones reales al desarrollo cultural local de Asia oriental y ver en sus marcos el origen de diferentes fenómenos culturales que se ponen de manifiesto en la Prehistoria del Nuevo Mundo. El estudio de las condiciones paleo-ecológicas del paso entre los dos continentes permitirá comprender mejor en qué momento el desarrollo cultural de America fue tributario directamente de las inmigraciones asiáticas y cuando tomó una vía independiente.

\section{INTRODUCCIÓN: HIPÓTESIS RELATIVAS AL ORIGEN DEL POBLAMIENTO DE AMÉRICA}

Los normandos, primeros europeos que encontraron indigenas americanos en el momento de su colonización de Groenlandia a partir de fi-

\footnotetext{
- Las figuras que ilustran este texto se deben a Elzbieta Sachse-Kozlowska y Barbara Drobniewicz (Varsovia), asi como a Peter Grob (Berna). Las piezas liticas de la ilustración están reducidas a la mitad de su tamaño aproximadamente.
} 
nales del siglo $x$ después de J. C., parece que no se preocuparon por conocer el origen de sus esquimales (inǔit). Por el contrario, los españoles, con el descubrimiento de América, se enfrentaron desde el principio con la pregunta: ¿de dónde habian llegado esos amerindios que ni siquiera eran mencionados en las Sagradas Escrituras? Canals Frau (1953), que describió muy bien esos problemas, demostró que ya en el siglo xvi el sabio español Arias Montano pretendia que los amerindios serian de origen semita y que habrian poblado el continente americano llegando desde el oeste. Aunque esta hipótesis no se basaba en hechos, fue aceptada sin oposición. "En general todo ocurría como si el origen semítico de los americanos tuviese la preferencia general» (CANALS FRAU 1953, pág. 11), y esto durante bastante tiempo. Sin embargo, hay que hacer notar que también existian sabios que querian ver semejanzas entre las altas civilizaciones de Egipto y las de América, lo que daba respuesta, según ellos, a la pregunta referente al origen de los amerindios. Además, no faltaban otros que creian que la legendaria Atlántida de Platón habia sido un puente terrestre que unía España y el Nuevo Mundo, sirviendo asi de camino de entrada.

Mientras que muchas de esas teorias hacian llegar a los amerindios del oeste, el paleontólogo argentino Florentino Ameghino desarrolló, a principios del presente siglo, una hipótesis según la cual había que buscar el origen de la humanidad en América (AMEGHINo 1906). Intentó demostrar que, en la parte austral de América del Sur, existia a mediados de la era terciaria un precursor del hombre que llamó Homunculus patagonicus. De esta forma animal habrían descendido unos homínidos primitivos a su vez precursores por una parte de los monos antropomorfos, y por otra del hombre representado por una especie a la que llamó Prothomos. No es necesario entrar en los detalles de esta teoria tan abstrusa como atrasada.

Una hipótesis, avanzada por primera vez en 1866 por el geólogo y paleontólogo inglés Boyd Dawkins (1866, 1874), es un poco más realista, pero tampoco es aceptable en la actualidad. Esta hipótesis, a la que se denomina la "teoría de la persecución del reno», pretendía que el medio ambiente a comienzos de Pleistoceno habia forzado a los renos y a sus cazadores a abandonar el Ártico americano, atravesar el estrecho de Bering y luego Siberia para llegar finalmente a la Europa occidental. Sus descendientes habrian sido los cazadores magdalenienses del Paleolítico superior. Hacia el final del Pleistoceno, la elevación de la temperatura habría forzado a los renos, y consecuentemente también a los magdalenienses, a desplazarse hacia el este. De esta forma habrian regresado finalmente al Ártico americano, en el que los actuales esquimales (inŭit) serian sus descendientes. 


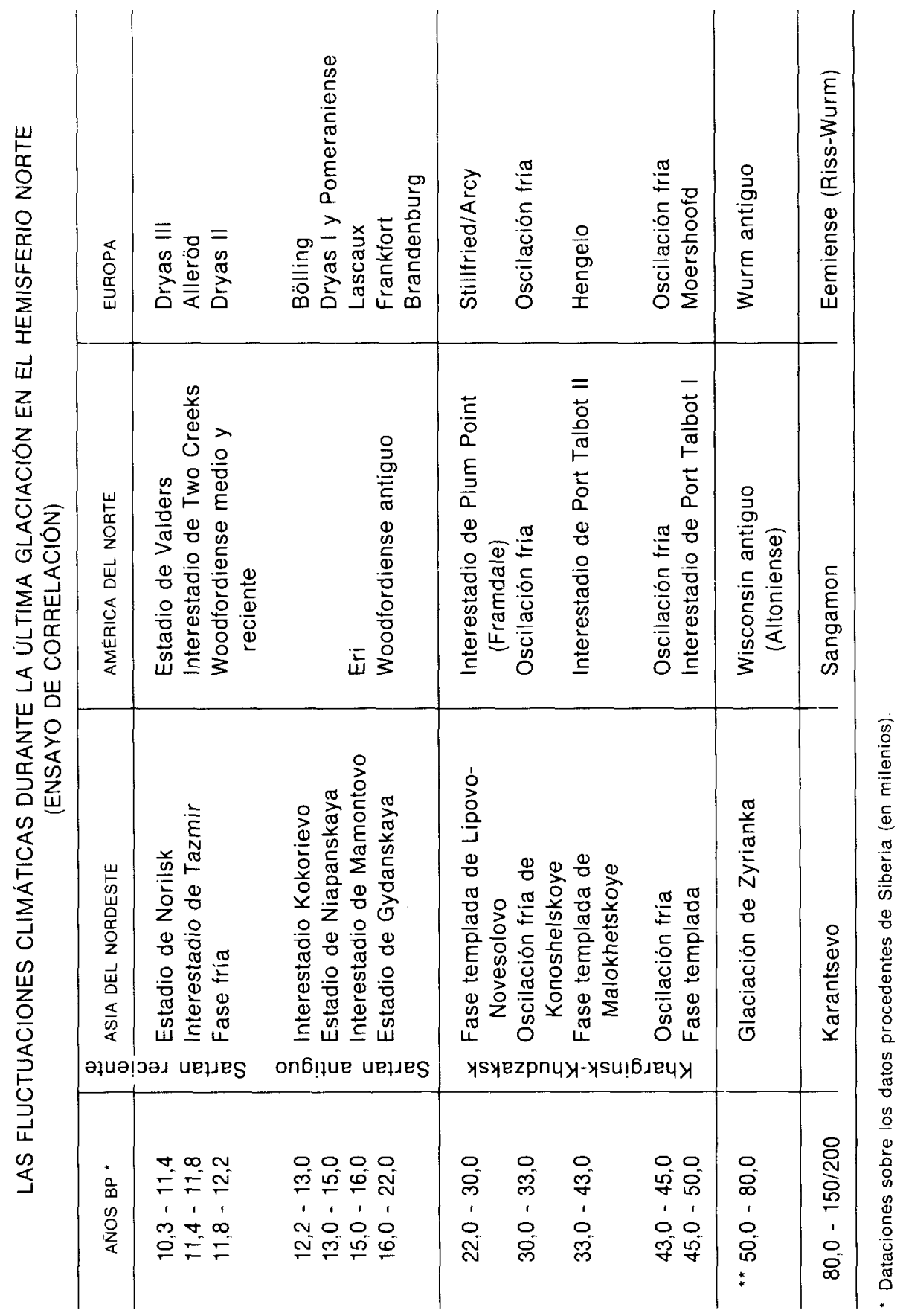




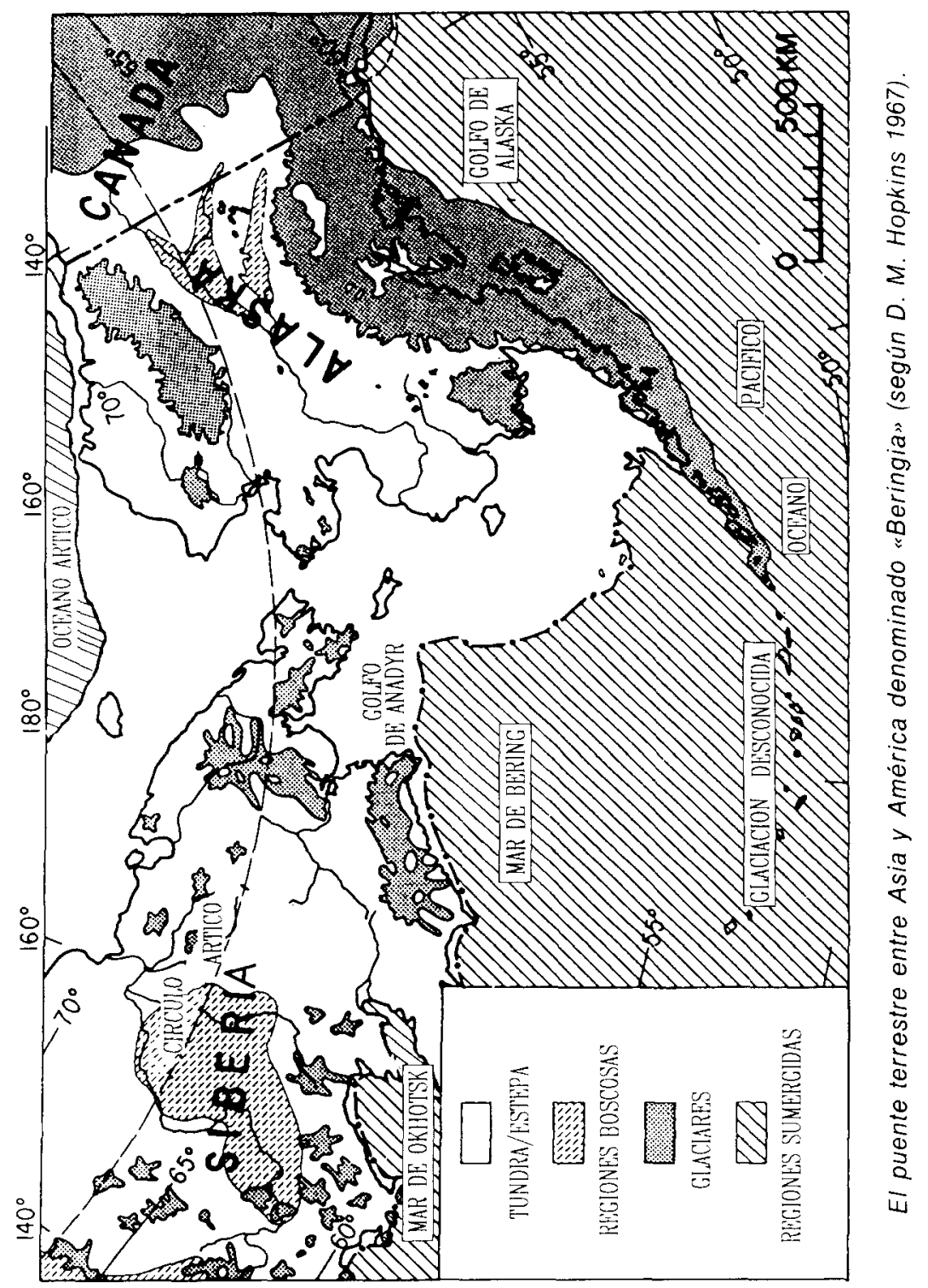


La idea según la cual el estrecho de Bering fue la puerta de entrada al Nuevo Mundo se vuelve a encontrar en una hipótesis muy importante presentada por el antropólogo americano de origen checo Alès Hrdlicka y su escuela en los años veinte (HRDLICKA 1925). En su opinión, era evidente que la cuna del hombre se encontraba en el Viejo Mundo. Estaba persuadido de que la infiltración en América se habia llevado a cabo en varios intentos y en una época bastante reciente, de oeste a este, habiendo servido el estrecho de Bering como puerta de entrada al Nuevo Mundo. Según él, los recién llegados procedian todos de Asia, eran racialmente uniformes y pertenecian al grupo Homo sapiens sapiens, siendo portadores de una civilización de tipo inferior que a continuación desarrollaron en América.

Aproximadamente en el mismo momento, el etnólogo francés Paul Rivet, sin rechazar la posibilidad o incluso la probabilidad de importantes infiltraciones por el estrecho de Bering, se limitaba a mostrar que el poblamiento del Nuevo Mundo no se habia sólo efectuado por la puerta de entrada septentrional, sino que numerosos elementos antropológicos, etnográficos y lingüisticos abogaban en favor de la infiltración de elementos malayo-polinesios, melanesios y australianos por otros caminos (RIVET 1925); incluso aceptaba la extraña hipótesis del portugués A. A. Mendes Correa según la cual algunos grupos australianos habrian podido llegar a América del Sur atravesando la región antártica (MENDES CoRREA 1928).

Finalmente, hay que señalar que en 1963 el americano E. F. Greenman publicó un trabajo en el que queria probar que el poblamiento del Nuevo Mundo se habia desarrollado hacia el fin del Pleistoceno, cuando algunos pueblos cazadores partiendo de la Europa occidental habrían atravesado el Atlántico con la ayuda de navios de tipo umiak y kayak (GREENMAN 1963).

Si se acepta que sabios de los siglos precedentes elaboraran teorias bizarras con referencia al poblamiento de América, se hace difícil comprender como, en nuestro tiempo y con el conocimiento de los trabajos de Hrdicka y de Rivet, el artículo de Greenman haya podido ser editado en una publicación periódica de reputación internacional.

Como veremos a continuación, nuestros conocimientos, aunque dejando abiertos múltiples interrogantes, se hallan lo suficientemente avanzados para establecer claramente que el poblamiento inicial de América no pudo realizarse mas que por la región en la que los dos continentes están separados actualmente por el estrecho de Bering. 


\section{CORRELACIONES ESTRATIGRÁFICAS DE LA ÚLTIMA GLACIACIÓN ENTRE EL NORDESTE DE ASIA Y AMÉRICA DEL NORTE}

El ritmo general de las fluctuaciones climáticas, alternancia de fases frias y templadas, era en principio parecido tanto en el Nordeste de Asia como en América del Norte después del último periodo interglaciar - Kazantsevo en Asia y Sangamon en América-. El ritmo de estas fluctuaciones seguia unas tendencias generales para todo el Hemisferio Norte, comportando dos Pleniglaciares (A y B) separados por el Inter-pleniglaciar correspondiente al Wurmiense medio en la terminologia europea.

El Pleniglaciar A, Ilamado Zyrianka en Siberia y Wisconsin antiguo (o Altoniense) en América del Norte, llegó a su final con anterioridad al $50.000 \mathrm{BP}$.

El Inter-pleniglaciar subsiguiente -denominado Kharginsk-Khudzaksk - entre 50.000 y $22.000 \mathrm{BP}$, comprende tres fases templadas separadas por dos enfriamentos considerables. La primera fase templada se sitúa entre 50.000 y 45.000 , la segunda - llamada Malokhetskoye- entre 43.000 y $33.000 \mathrm{BP}$, correspondiendo por tanto al interestadio de Port Talbot II en América, y la tercera - denominada Lipovo-Novoselovo- entre 30.000 y $22.000 \mathrm{BP}$, correspondiendo pues al interestadio de Plum Point (o Framdale) en América.

El Pleniglaciar B, denominado Sartaniense en Asia del Norte y Woodfordiense en América, se subdivide en dos etapas. La primera, que comprende los estadios glaciales Gydanskaya y Niapanskaya en Siberia, correspondería a la máxima extensión del inlandsis en América durante el Woodfordiense antiguo, antes de 13.000 BP. La segunda etapa, tardiglaciar, se caracteriza por el recalentamiento climático gradual y por el retroceso glacial, tendencias interrumpidas por al menos dos paradas del frente glacial, marcadas por estadios frios. El segundo de estos estadios, denominado Norilsk en Siberia y Valders en América, señala el final de los tiempos glaciales. Durante el periodo subsiguiente el recalentamiento se acentúa, llevando a las condiciones climáticas contemporáneas del Holoceno.

\section{EL PROBLEMA DEL PUENTE TERRESTRE ENTRE CHUKOTKA $Y$ ALASKA}

Se debe particularmente a la actividad del geólogo norteamericano David M. Hopkins el hecho de que la investigación referente al puente 
terrestre en la región en la que el estrecho de Bering separa hoy los continentes, asiático y americano, haya sido emprendida en los últimos años en un plano internacional por especialistas de diferentes disciplinas (Hopkins 1967). La sección de ciencias del Extremo Oriente de la Academia de Ciencias de la Unión Soviétiva organizó en 1973 un simposio internacional en el que los diferentes aspectos de este problema fueron ampliamente discutidos (Kontrimavichus 1976). El hecho que, durante el Pleistoceno reciente - como ya antes en múltiples ocasiones-importantes cantidades de humedad quedaban bloqueadas sobre tierra firme bajo forma de hielo, hizo que el nivel del mar bajara considerablemente: se estima que esta regresión alcanzaba los 90 ó 100 metros hacia el final de la época glacial. Su consecuencia era que, en muchos lugares, las zonas poco profundas del fondo del mar emergían, ampliando las regiones litorales y uniendo islas entre si o con la tierra firme. Este era el caso en la zona entre Siberia y Alaska, es decir, alli donde se extienden en la actualidad el mar de Tschuktchi y el mar de Bering. Las cartas marinas muestran que un descenso de 30 metros dejaba emerger un puente terrestre, que permitia - aunque muy estrecho- un paso a pie enjuto desde la peninsula de Chuktchi a la peninsula de Seward. Durante el máximo de la regresión, que corresponde al periodo más frio del Wisconsin, hacia $20.000 \mathrm{BP}$, el puente terrestre era sin duda mucho mayor: por el sur, su litoral se extendia desde el cabo Navarino en Siberia (a medio camino entre el cabo Desnev y la peninsula de Kamchatka) a la isla de Unimak en la parte oriental de la cadena Aleutiana; la orilla septentrional debió encontrarse muy al norte en el Océano Ártico. De esta inmensa llanura emergian en algunos lugares grupos de colinas que corresponden a las islas que existen hoy en dia entre Siberia y Alaska.

El puente terrestre, formando el centro de lo que actualmente se denomina Beringia, tenia sin duda hacia el final del Pleistoceno el mismo clima ártico que las regiones adyacentes de Siberia y Alaska: por tanto los veranos eran cortos y no muy cálidos, y los inviernos largos y duros. La vegetación no comportaba más que una tundra ártica, sin ningún árbol. Es posible que el terreno estuviera sembrado de lagos y lagunas y cortado por grietas debidas al hielo. Los rios que desembocan actualmente a lo largo de las costas de Siberia y de Alaska tuvieron que abrir su camino a través de la llanura que formaba entonces el puente terrestre de Bering; durante los cortos veranos, sin duda constituian obstáculos considerables, mientras que en invierno estaban cubiertos de hielo y, por ello, eran fáciles de atravesar. La fauna era la misma que la que nos es conocida para el final del Pleistoceno, en forma de restos fósiles, en Siberia y en Alaska: sólo mencionaremos aqui algunos grandes mamiferos terrestres como el mastodonte, el mamut, el bisonte, el reno, el buey al- 
mizclero, el oso pardo, el lobo, etc.; en las islas como Diomèdes, San Lorenzo, San Mateo y Nuvinak, se han encontrado testimonios de su presencia en el pasado bajo la forma de osamentas fósiles. Beringia estaba también habitada sin duda por un gran número de pájaros, tanto terrestres como marítimos, y en sus ríos podemos imaginar grandes cantidades de salmones y otros peces. Por otra parte, las regiones litorales, probablemente llanas y bordeadas en algunos lugares por lagunas, eran seguramente visitadas periódicamente por las focas, las morsas y los osos polares.

Hacia el $17.000 \mathrm{BP}$, la subida del nivel del mar empezó a disminuir de forma continua la extensión del puente terrestre. Incluso es posible que este nexo entre los dos continentes hubiera quedado totalmente sumergido durante la primera mitad del XII milenio antes de nuestra era, es decir, durante el interestadio de Two Creeks americano, correspondiente al interestadio de Taymir en Asia. Pero, a partir del estadio de Valders, el paso quedó de nuevo garantizado durante algunos miles de años. La definitiva separación se hizo efectiva entre 10.000 y 8.000 BP. Desde entonces, el paso a pie enjuto era imposible durante los veranos, y en invierno extremamente dificil a causa de la cobertura muy irregular del hielo constantemente en movimiento.

Aún debemos mencionar que hay autores, como P. Bosch-Gimpera (1962), que han supuesto la posibilidad de que la cadena de las islas Aleutianas hubiera podido servir igualmente de puerta de entrada de un continente al otro. Pero, por una parte, las cartas marítimas nos muestran que nunca un puente terrestre sin vacíos considerables pudo existir hacia el final del Pleistoceno; por otra parte, hecha abstracción del tema de las embarcaciones practicables, un viaje en canoa habria exigido un recorrido de $450 \mathrm{~km}$ en un mar muy peligroso desde Kamtchatka hasta Attu en el extremo oriental de las islas Aleutianas -distancia enorme, sólo interrumpida por los islotes del Comendador, prácticamente imposible de atravesar en la época en cuestión.

\section{LAS GLACIACIONES DE LA AMÉRICA DEL NORTE DURANTE EL WISCONSIN RECIENTE Y EL PROBLEMA DE LA COMUNICACIÓN ENTRE BERINGIA Y EL SUR DEL SEMICONTINENTE NORTEAMERICANO}

Como se ha visto en el epigrafe 2, la correlación de los estadios e interestadios durante la segunda mitad de la última glaciación en Eurasia 
y en América es bastante clara. Aproximadamente se puede constatar la misma secuencia de avances y de paradas o retrocesos del hielo en América del Norte y en Asia del noroeste. Lo que es importante para nuestro problema, o sea para los inicios del poblamiento del Nuevo Mundo, es la extensión del hielo durante este periodo, a la vista de las consecuencias que ello debia tener para la inmigración del hombre. Como hemos visto en el epigrafe precedente, la situación en Asia del noroeste, donde no existía una cobertura total de hielo, permitía el acceso a Beringia, siendo siempre posible el puente terrestre; del mismo modo, el camino de inmigración en la parte noroeste de Alaska no estaba bloqueado. Pero más al sur, en el Canadá y en la parte norte de los Estados Unidos, el hielo formó una barrera total durante algunos miles de años. El hielo, llegado del este del Ártico americano (este del territorio de Quebec, regiones litorales del Labrador, Tierra de Baffin, Tierra de Ellesmere) y los glaciares que descendian de las Montañas Rocosas, seguían ampliándose hasta alcanzar su máximo hacia $18.000 \mathrm{BP}$; esto corresponde, como hemos visto en el epigrafe 2, al período del Woodfordiense antiguo.

Mientras tanto, Alaska quedaba en parte libre de hielo y formaba por tanto, con el puente terrestre, una prolongación de Siberia. H. Müller-Beck (1966, pág. 385) piensa que el periodo durante el cual esta inmensa barrera de hielo separaba el norte y el sur del semicontinente norteamericano empezó como máximo hacia el 30.000 y se terminó, como más tarde, alrededor de 10.000 antes del tiempo presente. El periodo durante el cual la cobertura de hielo se extendió sin interrupción a través de todo el continente norteamericano fue probablemente un poco más corto, es decir, que se puede fijar entre 25.000 y $15.000 \mathrm{BP}$; durante su extensión máxima, en el periodo del Woodfordiense antiguo, el hielo, cuya superficie era cinco veces más grande que la que cubria en la misma época el norte de Europa, llegaba hacia el sur hasta el $38^{\circ}$ de latitud. Se supone que, después del $15.000 \mathrm{BP}$, o sea en el periodo que correspondia a los interestadios de Kokorievo y de Bölling en Asia del noroeste y en Europa, empezó a abrirse un corredor que permitia la reactivación de la comunicación entre las dos regiones separadas totalmente durante varios miles de años; este corredor se encontraba al este de las Montañas Rocosas.

\section{LA APARICIÓN DEL HOMBRE EN AMÉRICA ANTES DEL CIERRE DEL CORREDOR CONTINENTAL DURANTE LA TRANSGRESIÓN MÁXIMA DEL WOODFORDIENSE}

El problema de los hallazgos arqueológicos que atestiguen la aparición del hombre en América antes de la transgresión máxima del Wood- 


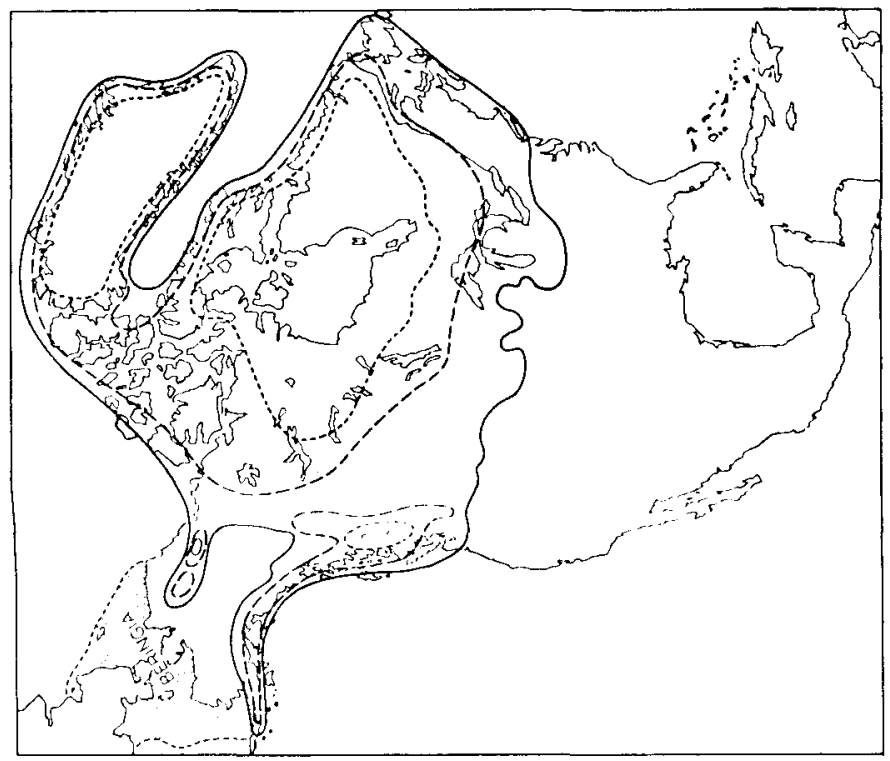

Extensión del hielo en América del Norte durante el Woodfordiense, entre 20.000 y 8.000 BP. Linea seguida, 20.000-18.000; trazos largos, $12.000 \mathrm{BP}$; trazos cortos, 8.000 BP; puntillado, extensión máxima de Beringia, 20.000-18.000 BP. (Según D.

D. Anderson 1968).

fordiense antiguo es objeto de la atención de los investigadores y sigue siendo tema de discusiones. Las controversias derivan tanto del número muy limitado de hallazgos como de su documentación arqueológica y estratigráfica, en muchos casos insuficiente. La critica severa de estas fuentes nos conduce a la conclusión que hay que distinguir dos grupos de hallazgos: los anteriores al 22.000-24.000 BP son discutibles y no prueban de forma suficiente la existencia del hombre paleolítico en el Nuevo Mundo; por el contrario, los que datan de ese periodo y atestiguan la presencia del hombre son desgraciadamente poco numerosos y no siempre bien estudiados.

La critica de las evidencias de la actividad del hombre en América tiene que considerar en primer lugar la datación de los yacimientos y el carácter intencional de los artefactos encontrados en esos lugares. Serias dudas referentes a la datación podrian plantearse en lo que se refiere a los hogares acompañados de industria de Santa Rosa Island, California (OrR 1968), donde, junto a una muy antigua fecha hacia $37.000 \mathrm{BP}$, existe 
para el mismo nivel una datación igualmente radiométrica mucho más reciente de aproximadamente $11.800 \mathrm{BP}$. El problema de la incoherencia de la datación radiométrica se plantea igualmente por el hallazgo paleoantropológico de los restos humanos de Taber, en Canadá, atribuidos a 40.000 BP (STALKER 1977), aunque haya allí tambièn fechas más recientes.

Diversos yacimientos de fechas anteriores al 22.000-24.000 BP son dudosos a causa del carácter intencional de los artefactos, insuficientemente probado. En ciertos casos se trata de hallazgos mencionados desde hace mucho tiempo en la literatura científica (por ejemplo, Tule Springs, Nevada y Lewisville, Texas; KrIEgER 1964) o de hallazgos relativamente recientes en los que el propio carácter de los sedimentos geológicos sugiere la acción de factores naturales, como, por ejemplo, los depósitos fluvio-glaciares (till deposits) de Shegguiandah. Ontario, fechados en $30.000 \mathrm{BP}$ (SANFORD 1971), o bien el lugar de El Bosque, en Nicaragua, fechado cuidadosamente por el estudio geológico en más de 30.000 años $B P$, pero desgraciadamente sin ninguna pieza indiscutiblemente tallada (PAGE 1978).

Los yacimientos que no han proporcionado más que piezas en hueso, sin ningún contexto litico, merecen una crítica especial. Se trata sobre todo del lugar de Old Crow, en el norte del Canadá, y del de American Falls, en Idaho, ambos fechados en un periodo que precedió al Woodfordiense antiguo. A pesar de los esfuerzos realizados para probar el carácter intencional de los objetos en hueso de Old Crow (BonNichsen 1978, IRVING 1968, 1971, 1978), el papel de los factores naturales en su hechura y su modificación es indiscutible. Estas observaciones criticas se refieren tanto a la localidad 11, para la que las dataciones entre 30.000 y 43.000 años BP han sido publicadas, como para la localidad 12, donde los huesos estaban recubiertos por los depósitos atribuidos al interglaciar Sangamon, subyacentes a Old Crow Tephra y fechados en 80.000 años (IRVING et al. 1986). Añadamos que el examen de los objetos líticos encontrados "en las inmediaciones" de los seudo-artefactos liticos (que nos fueron mostrados muy amablemente en el Departamento de Antropologia de la Universidad de Toronto) contiene puntas foliáceas y lascas de la talla bifacial cuya edad es ciertamente holocena. Añadamos que en el Viejo Mundo no se conoce ninguna cultura que haya utilizado únicamente objetos de hueso; los hallazgos en hueso que tendrian que atestiguar la etapa pre-litica, como el estadio osteodonquerático del comienzo del Paleolitico, han sido sometidos igualmente a severas críticas. El argumento citado por A. Bryan (1978) de que el estudio de las primeras etapas del desarrollo cultural de América exigirá la identificación de unas técnicas especiales, desconocidas en otras partes, no es convincente. Aunque se 
pudiera suponer tal fenómeno en las etapas iniciales de la cultura humana, es inverosímil suponer que unas poblaciones surgidas del Paleolitico superior hubiesen abandonado completamente sus tradiciones tecnológicas. Recordemos que, incluso en las condiciones de gran aislamiento de los grupos del Paleolítico medio y superior en el Viejo Mundo, tal fenómeno no ha sido observado. Por ello hay que admitir que los primeros habitantes de América disponian sin duda de los mismos principios tecnológicos para tallar la piedra -materia prima fácilmente accesible casi en todos los territorios de su gran migración-, que sus antepasados asiáticos.

Se podrán añadir, además, diversos sitios descubiertos recientemente: Meadcroft, Pensylvania; Bluefish Caves, Yukon Territory, Canadá; Taimtaima, Venezuela; Orogrande Cave, New Mexico. Asimismo hay que señalar que algunos genetistas y linguistas creen poder demostrar que la infiltración en el doble continente americano tuvo lugar en un período al que se denomina "Pre-Clovis" y que podría corresponder a fechas de 30.000 años BP o incluso más.

En los que se refiere al periodo que empieza hacia $20.000 \mathrm{BP}$, los más importantes hallazgos son sin duda algunos hogares $u$ otros restos de combustión acompañados de material litico indiscutiblemente tallado. Este es el caso de los yacimientos arqueológicos descubiertos en las orillas del lago Chalco, cerca de Ciudad de México: Tlapacoya I (24.000 士 $4.000 \mathrm{BP})$ y Tlapacoya III (21.700 $\pm 500 \mathrm{BP})$. La serie de productos en andesita de Tlapacoya I comprende lascas y hojas, obtenidas de núcleos con un plano de percusión y de extracción ancho y no preparado (fig. 1); observemos, con todo, que una lasca en cuarcita obtenida de la parte superior de un núcleo para hojas atestigua la preparación más cuidadosa de los núcleos (MIRAMBel 1978, figs. 8 y 9). Una edad similar puede ser atribuida a una hoja de obsidiana procedente de Tlapacoya $\|$, obtenida de un núcleo con dos planos de percusión opuestos, muy desarrollado desde el punto de vista tecnológico (fig. 2). Por el contrario, la punta foliácea evocada en el informe de la señora Mirambel (1978), procedente de Tlapacoya I, no ha sido reconocida en relación con los hogares fechados hacia 20.000 , sino que fue penetrada por las krotovinas de un sedimento más reciente, cuya fecha seria de aproximadamente $15.000 \mathrm{BP}$.

La datación próxima a los $20.000 \mathrm{BP}$ ha sido reconocida asimismo para la base de la cueva Pikimachay, en Perú (MAC NeISH et al. 1970, 1971), que ha proporcionado una industria lítica del “complejo de Paccaicasa". Esta industria comprende muchas lascas y choppers bastante toscos, cuyo carácter intencional no está desgraciadamente fuera de duda. Hay que subrayar que en la secuencia de la cueva de Pikimachay las 

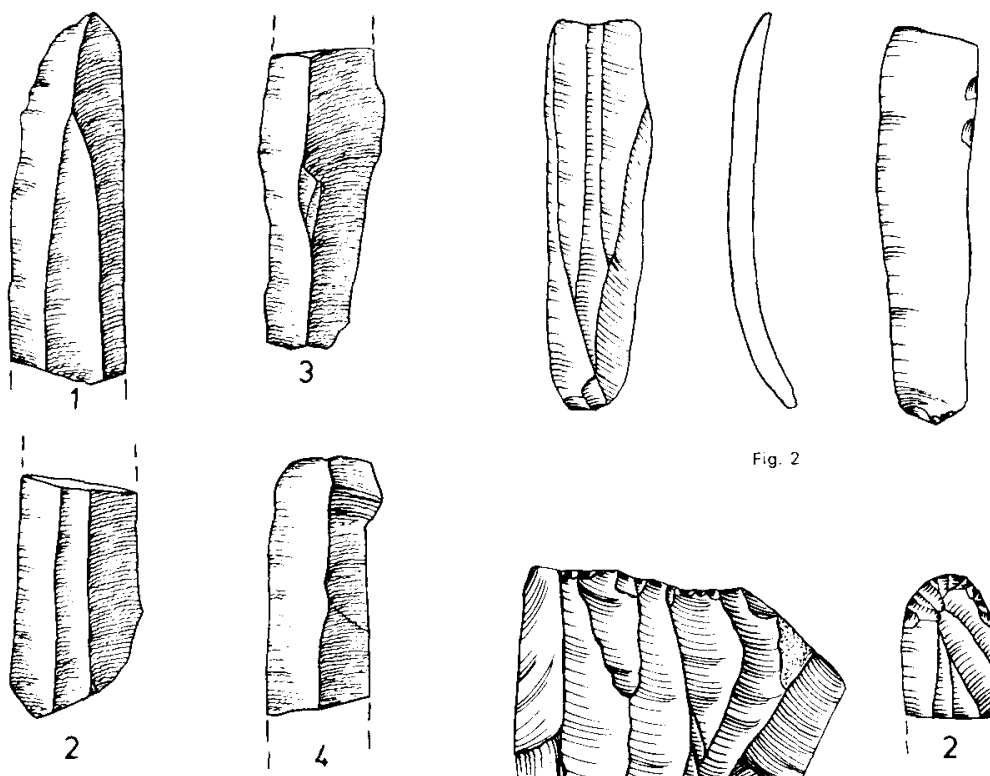

Fig. 2
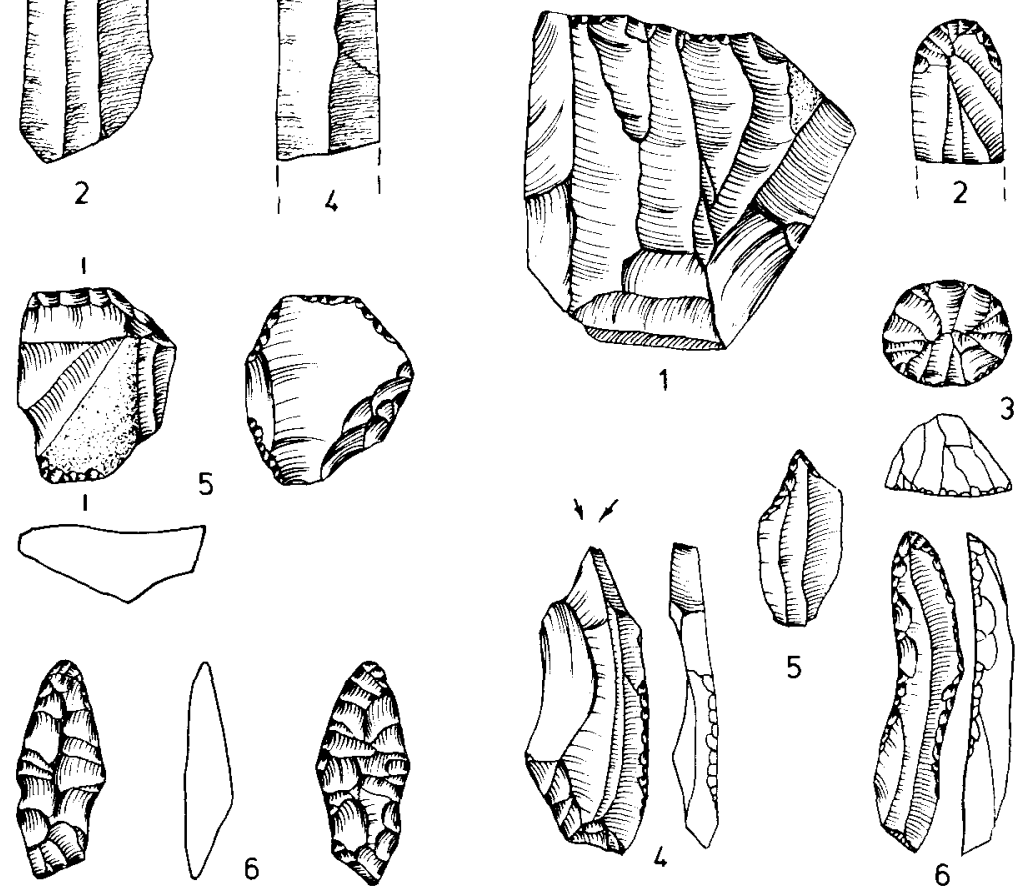

Fig. 1

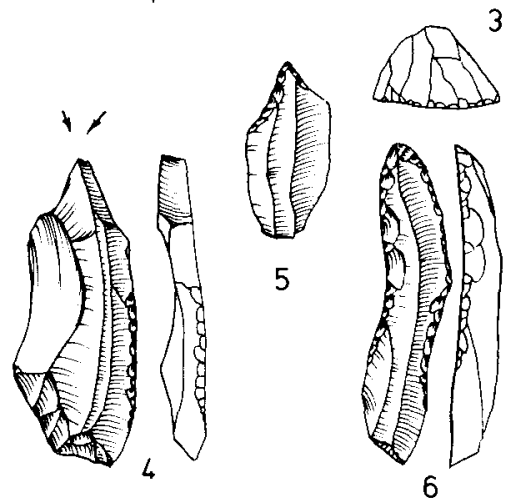

Fig. 1. Industria litica de Tlapacoya (México): 1-4 hojas en andesita, 5 lasca retocada, 6 punta foliácea (según L. Mirambel 1978).

Fig. 2. Tlapacoya (México): hoja de obsidiana.

Fig. 3. Malta, a orillas del rio Belaya (cuenca del Angara, Siberia): 1 núcleo, 2 raspador, 3 núcleo cónico para hojitas, 4 buril diedro, 5 perforador, 6 hoja retocada. 
primeras puntas foliáceas solo aparecen en los niveles más recientes, fechadas aproximadamente en el $14.000 \mathrm{BP}$, en el marco del “complejo Ayacucho".

Otras lascas y hojas han sido encontradas en la región de la presa Valsequillo, en México, también con dataciones de unos 20.000 BP. Señalaremos en particular una hoja muy regular, con la parte distal rota, encontrada en el nivel $J$ del yacimiento de Hueyatlaco (IRWIN-WILLIAMS 1967), y una lasca retocada en la parte distal, procedente de los depósitos aluviales de Cualpan, fechados en 21.850 \pm 850 BP (SzABo et al. 1969).

De esta enumeración de los más antiguos hallazgos de objetos indiscutiblemente tallados en América resulta que atestiguan la presencia de la técnica de lascas y de la técnica laminar al propio tiempo que la ausencia de la técnica bifacial y de objetos foliáceos. La técnica de lascas está basada en núcleos simples con un plano de percusión, a veces pasando a los choppers (Paccaicasa); por el contrario, la técnica laminar está mucho más desarrollada, atestiguando tanto la utilización de los núcleos cónicos con un plano de percusión, con preparación, como de los núcleos con dos planos de percusión opuestos (Tlapacoya II). Hay que admitir pues que en las más antiguas industrias de América existe al mismo tiempo el elemento más primitivo, con lascas y con choppers, y el elemento más desarrollado, típico del Paleolítico superior. Desgraciadamente, el escaso número de hallazgos liticos, y en particular la pobreza de los utensilios retocados, no nos permite caracterizar estas industrias desde el punto de vista morfológico; se puede constatar únicamente la presencia de retoques marginales y la ausencia de retoque bifacial, que aparecerá más tarde. En este sentido nos unimos, pues, a la opinión de Lynch (1974) que critica la idea de una «tradición con bifaces y con choppers" como característica para la más antigua etapa de la prehistoria americana, y atribuyendo a este estadio los utensilios sobre lascas. Pero, al mismo tiempo, tenemos que completar la característica de este estadio con la aplicación de la técnica laminar, lo que incluye asimismo la noción del lower lithic introducida por I. Rouse (1976), que tampoco acepta la presencia de la técnica laminar en este estadio.

Por último, hay que evocar la hipotesis de A. Bryan (1973) que atribuye a los primeros americanos un flexible tool kit que podria evolucionar tanto a la técnica bifacial como a la bifacial. Dada la larga experiencia y tradición tecnológica que necesitan la aplicación tanto de la técnica bifacial laminar como la técnica bifacial foliácea, seria poco probable que tal fenómeno hubiese tenido lugar en América, y aún más por el hecho de que en todas partes en el Viejo Mundo estas tradiciones tecnológicas no divergen fácilmente de un fondo común, sobre todo en un periodo tan corto. 
La posición que aquí adoptamos se acerca más a la presentada por C. Vance-Haynes (1971) que en primer lugar opuso los hallazgos dudosos (questionable human workshop) de la etapa más antigua (Early Paleo-Indian) a los indiscutibles utensilios de la etapa media (Middle Paleo-indian), y a continuación estos con las puntas foliáceas de la etapa reciente (Late Paleo-Indian). El carácter lítico de la etapa media (flake-blade-unifacial scrapers) y su encuadre cronológico (Farmdalian-Early Woodfordian) se hallan bastante cerca de nuestra caracterización de las más antiguas industrias de América, cuyo origen precede al cierre del corredor continental por la extensión máxima de los glaciares.

Las tradiciones líticas de la etapa inicial que aqui hemos caracterizado, comportando choppers, lascas y hojas, desempeñaron sin duda un papel importante en el desarrollo autónomo de las industrias de América del Norte y del Sur en el periodo del Woodfordiense antiguo, después de la formación de la barrera de hielo. Un vasto abanico de utillajes más recientes, sobre todo con choppers y con lascas, ha sido estudiado por diversos autores después de Krieger (1964). Los hallazgos de Borden $(1965,1975)$ atribuidos al complejo Pasika en el Lower Fraser Canyon atestiguan probablemente un movimiento de esta tradición en el sentido opuesto, del sur al norte, en el periodo del retroceso glaciar hacia el $13.000 \mathrm{BP}$.

Pero, si se tiene en cuenta que R. Bonichsen ha vuelto a las ideas de Rivet y Mendes Correa acerca de una infiltración en América llegada desde Australia y pasando por el Antártico, o que el mismo autor habla de la posibilidad de una travesia del Pacífico viajando por las islas, es bien lógico preguntarse para que sirve todo esto. Algo semejante ocurre con la hipótesis del frances N. Guidon, el excavador de Pedra Furada, que pretende que no puede excluirse la posibilidad de una travesia del Atlántico a partir de África.

Observemos, finalmente, que el americano D. J. Meltzer menciona la posibilidad de que algunos grupos humanos hubiesen podido llegar muy pronto a América, pero que se extinguieron antes de que otros les siguieran (HORGAN 1992).

\section{LA SITUACIÓN CULTURAL EN ASIA DEL NORDESTE ANTES DEL PERIODO DE SARTAN}

Las más antiguas industrias de la Siberia del nordeste son discutibles bajo diversos aspectos y precisan de una crítica severa antes de ser 
aceptadas. El problema principal está planteado por los yacimientos atribuidos al Paleolítico inferior, fechables en el periodo anterior a la glaciación de Zyrianka, o los del Paleolítico medio, datando esta vez del periodo Zyrianka y parcialmente del de Karginsk-Khudzaksk. Los choppers hallados en el Ulainka (Derevianko 1978) y en Filimochki (Powers 1973) son por 10 general atribuidos al Paleolitico inferior, aunque algunos autores han expresado dudas relativas a estos utensilios, considerándolos más bien como productos naturales (IVANOVA 1969). También hay que tratar con extrema prudencia la fecha propuesta por Derevianko (1969) para los choppers Kumara I, a orillas del Angara, que atribuye al Pleistoceno medio, sin ningún argumento geológico. La misma observación hay que hacer para el yacimiento de Kumara II; los argumentos estratigráficos y geológicos para la datación de este lugar ya fueron considerados insuficientes por Powers (1973).

Las mismas observaciones críticas hay que hacer a los hallazgos de Diringh-Youriakh, en la $V^{a}$ terraza del Lena, cuya edad ha sido situada entre 1 y 2 millones de años. La revisión critica y las discusiones en torno a este yacimiento durante el coloquio de INQUA en 1990 no permiten ya ninguna duda en cuanto al carácter de este descubrimiento.

Con frecuencia se atribuye al Paleolítico medio el yacimiento de la cueva Ust-Kanskaya (Roudenko 1960), opinión compartida por los investigadores americanos (WILLEY 1971). Desgraciadamente también, esta opinión no puede ser aceptada sin reservas, habida cuenta de la revisión crítica de la estratigrafía geológica de esta cueva (TSEITLIN 1972) y de la subdivisión del material lítico en dos series: la del Paleolitico medio y la del Paleolitico superior. Según Mochanov (1976) esta subdivisión fue establecida después de las excavaciones. Por tanto, es dificil aceptar sin reservas la atribución de este lugar al periodo anterior al inter-pleniglaciar Kharginsk-Khudzaksk.

En el estado actual de nuestro conocimiento del problema, el hábitat humano en la región del nordeste de Siberia parece ser pues un fenómeno bastante reciente, que precede en poco tiempo al comienzo del Sartan. Está fuera de duda que los más antiguos conjuntos del área que nos ocupa se caracterizan por técnicas y utensilios de tipo arcaico, que evocan el Paleolitico medio o incluso inferior, pero estos elementos van siempre acompañados de una técnica laminar desarrollada, característica del Paleolitico superior. Ello nos autoriza a comparar estas industrias, a pesar de sus componentes arcaicos, con las industrias del Paleolítico superior en las demás partes del Viejo Mundo. Las implicaciones de esta constatación para el origen del poblamiento de América son importantes: los antepasados asiáticos de estos pobladores hay que buscarlos única- 
mente en el Paleolítico superior del Viejo Mundo, en un período que siguió al paso del Paleolítico medio al Paleolitico superior. Esta transición tuvo lugar en todo el territorio entre Europa y Siberia en el periodo entre 40.000 y $30.000 \mathrm{BP}$.

En Siberia oriental las más antiguas industrias con carácter indiscutiblemente humano datan del final del periodo de Kharginsk-Khudzaksk y del comienzo del Sartaniense. Se caracterizan principalmente por el elemento chopper y por utensilios sobre lascas, acompañados siempre de la técnica laminar. Los más antiguos utillajes de este tipo han sido señalados por J. A. Mochanov (1977) en Eshantsy en la cuenca del rio Aldan, y atribuidos a la fase antigua de la cultura de Diuktai, aunque no presentan aún la técnica del retoque invadiente bifacial, característica de esta última cultura. Eshantsy, fechado en $35.000 \mathrm{BP}$, ha proporcionado choppers tipicos (fig. 4), núcleos de hojas y de lascas, con uno o dos planos de percusión, asi como núcleos en forma de quilla (del tipo Gobi) para hojitas. Hay pocos utensilios retocados: buriles (21), lascas retocadas (4), raspadores (3), raedera (1) y perforador (1). Un utillaje similar, atribuido por Mochanov al mismo periodo, procede de Ikhine 1 y contiene asimismo los núcleos en forma de quilla para hojitas.

Z. A. Abramova (1980) ha publicado recientemente algunas observaciones críticas acerca de la datación de los yacimientos de la cuenca del Aldan en el periodo inter-pleniglaciar de Kharginsk-Khudzaksk. Esta autora subraya particularmente que la relación entre las dataciones anteriores a 20.000 BP procedentes de las terrazas del Aldan y las industrias de Eshantsy, Ikhine y Ust-Mil no es indiscutible. Seria deseable un nuevo estudio geológico y estratigráfico con el fin de fijar la posición de los yacimientos en cuestión, dado que contienen diversos elementos tipológicos característicos de las etapas recientes del Paleolítico de Siberia.

Un poco más recientes que los utillajes de Eshantsy, los de Afontova Gora II, nivel C3, y de Afontova Gora III, se fechan en torno al 20.000 BP, por tanto en los comienzos del periodo Sartan. Estos conjuntos se caracterizan por la coexistencia de la técnica de choppers y de lascas junto con la de hojas. Entre los núcleos se encuentran ejemplares con un plano de percusión, algunos evolucionando hacia los choppers, junto con piezas más regulares con la cara de explotación plana, presentando en ocasiones una preparación lateral que evoca la de los núcleos levalloisienses. Las hojitas eran obtenidas exclusivamente a partir de los núcleos de tipo Gobi. Los utensilios retocados comprenden raederas $(45 \%)$, sobre todo laterales convexas, raspadores $(21 \%$ ) tanto sobre hoja como sobre lasca, y muchas piezas esquirladas. Las hojitas microlíticas fueron utilizadas sin retoques como armaturas de puntas con ranura. Hay que hacer notar que 

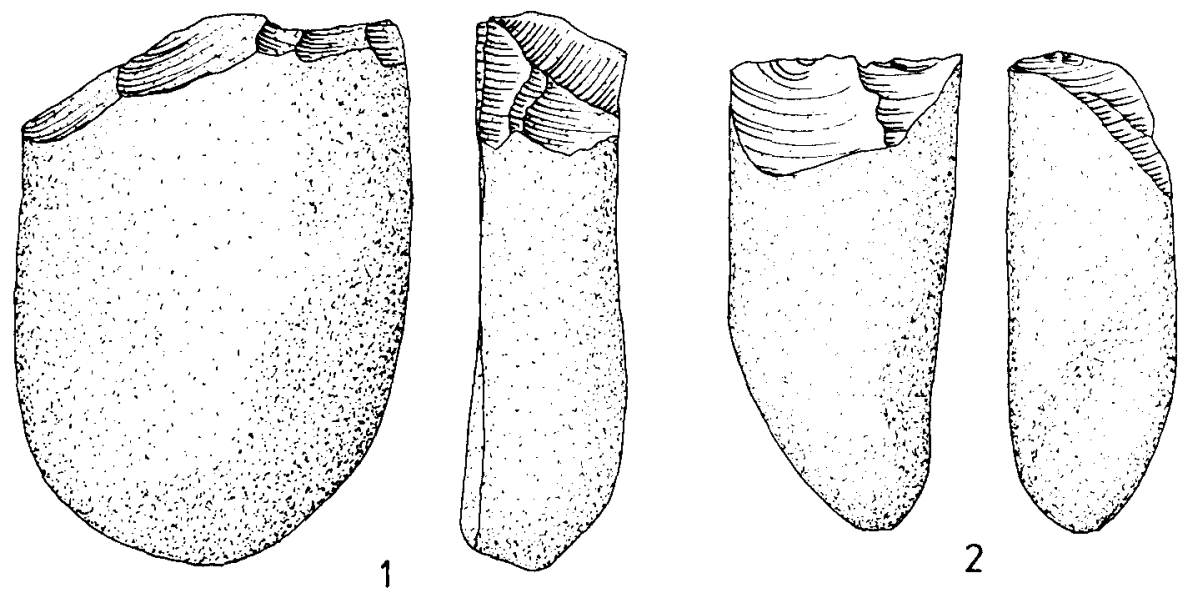

2
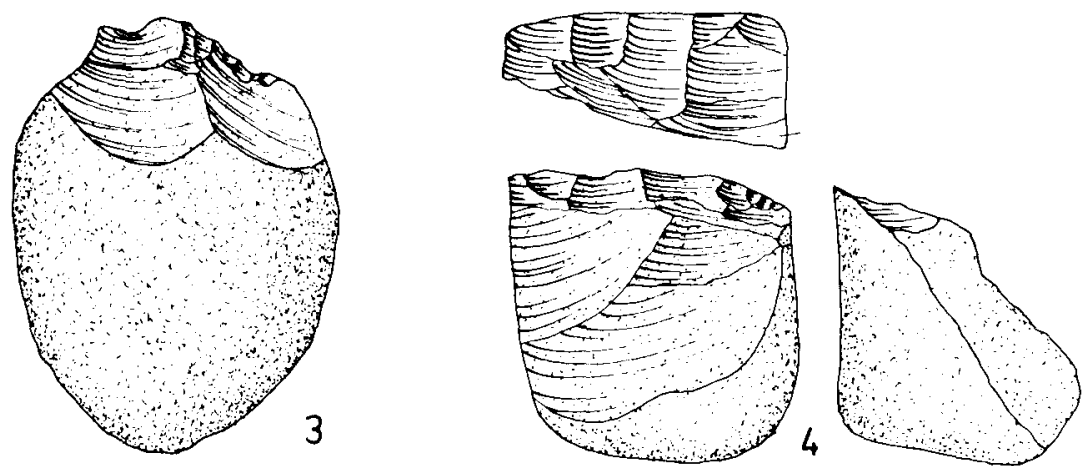

Fig. 4. Eshantsy a orillas del Aldan (Siberia): 1-4 choppers (según J. A. Mochanov 1977).

el retoque abrupto para las puntas de dorso falta en absoluto, como, por otra parte, en todos los conjuntos siberianos orientales, lo que constituye la diferencia más importante entre las industrias de Siberia y las del Paleolítico superior europeo y del Próximo Oriente. En la cultura Afontova Gora los utensilios en hueso están bien representados, incluyendo las azagayas con acanaladura y las azagayas de sección oval o muy aplanada.

Paralelamente con las industrias con choppers y con hojas se encuentran en Siberia otras con técnica únicamente laminar, representadas sobre todo por la cultura de Malta-Buret'. En esta cultura se tallaron hojas a partir de núcleos con un solo plano de percusión o a partir de núcleos 


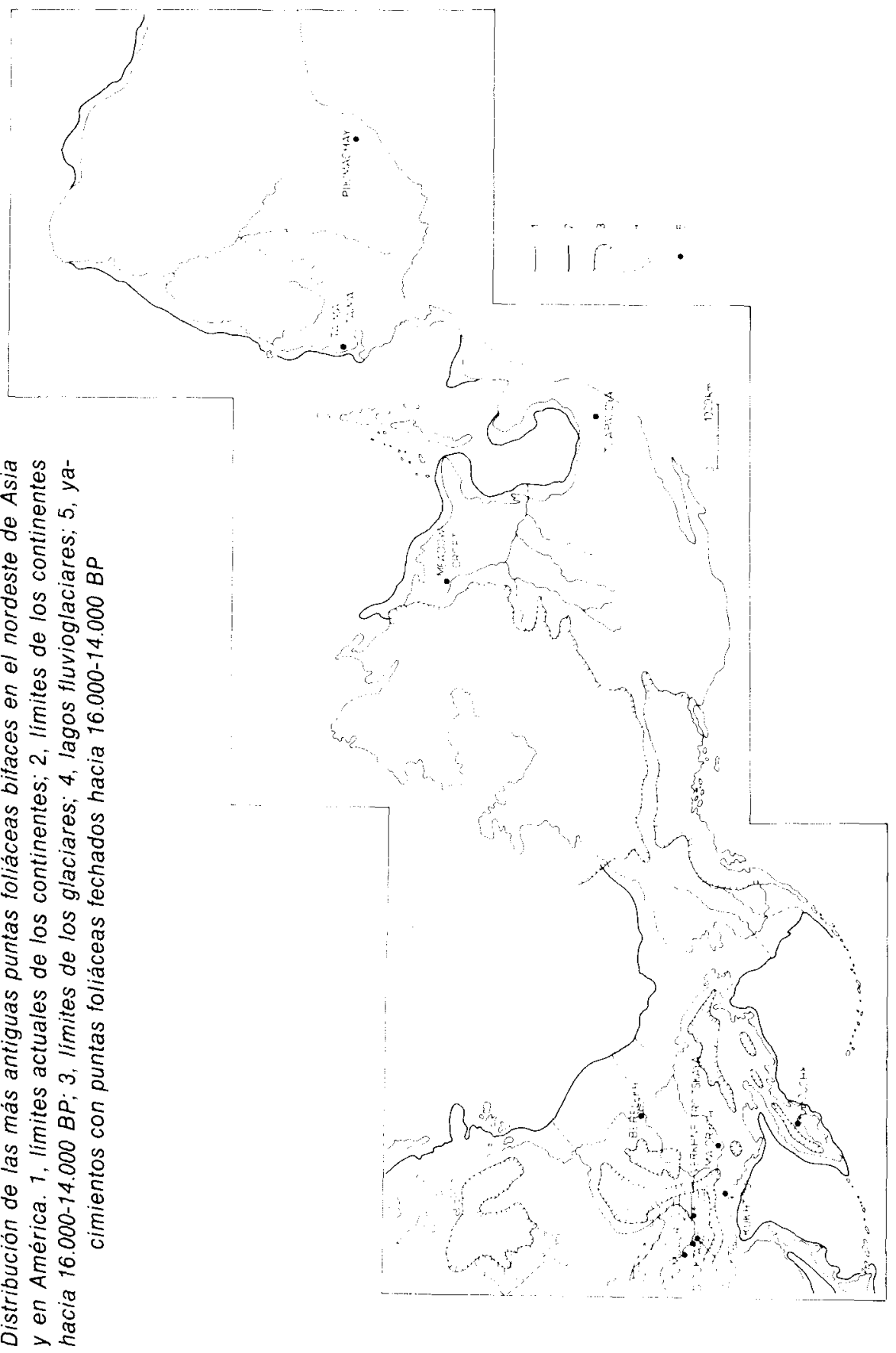


globulosos. Estas hojas son bastante cortas y poco regulares. La técnica de Gobi, con un núcleo en quilla, falta en absoluto. Entre los utensilios retocados aparecen sobre todo las hojas retocadas (38\% en Malta), los buriles, los perforadores $(30 \%$ ) y los raspadores $(21 \%$ ) (fig. 3). Obsérvese, asimismo, la ausencia absoluta de hojas de dorso. Son bien conocidas las manifestaciones del arte de la cultura de Malta-Buret', en ocasiones relacionadas con el arte occidental del Estilo II de A. Leroi-Gourhan (1965). En nuestra opinión estas analogías son debidas más bien a un sistema similar de adaptación de los cazadores de mamuts que a las verdaderas conexiones o afiliaciones culturales. También se relaciona la cultura de Malta-Buret' con el Auriñaciense occidental, sobre todo tomando como base la presencia de los raspadores llamados carenados. El examen de las piezas procedentes de Malta demuestra que difieren de los verdaderos raspadores carenados auriñacienses. Las partes frontales no son convexas, no tienen perfil carenado y están formados por una serie de extracciones de hojitas rectas. Se trata pues de un núcleo especial y no de un utensilio especial.

Independientemente de las industrias descritas hasta aqui, en el sudeste de Siberia existen otras con la técnica Levallois y laminar, así como algunas que están caracterizadas por la técnica Levallois y por los choppers. Las primeras están bastante extendidas en Mongolia, donde se constata la presencia de utillajes con elevados elementos levalloisienses acompañados de utensilios sobre hojas del tipo Paleolitico superior (OKLADNIKOV 1962, LARITCHEV 1964, KozLOWSKI 1970). Los utillajes de este tipo son conocidos en China donde datan del periodo entre 28.000 y $13.000 \mathrm{BP}$ (JIA LANPO 1979). Recientemente, la presencia de industrias similares ha sido señalada en la zona sudoeste de Zabajkale, por tanto mucho más al norte de lo acostumbrado; se trata en particular del yacimiento de Tolbaga (KONSTANTINOV 1980), fechado por el radiocarbono en $34.860 \pm 2.100$ y $27.210 \pm 300 \mathrm{BP}$ (fig. 5).

La coexistencia de la técnica levalloisiense con la de los choppers ha sido situada en la región de Primorie, es decir en el litoral del Pacífico al sur de Kamtchatka (OKLadnikov 1969, Derevianko 1978, Powers 1973). Desgraciadamente la posición cronológica de los yacimientos que contienen estos elementos sigue siendo incierta y es posible que no aparezcan antes del Sartaniense reciente (figs. 6 y 7 ).

La revisión de la situación en la Siberia oriental para el periodo preSartaniense/Sartaniense-antiguo nos lleva a las siguientes conclusiones:

1. Todos los tecno-complejos mencionados debidos a la interferencia de los choppers y de la técnica levalloisiense y laminar tienen un 

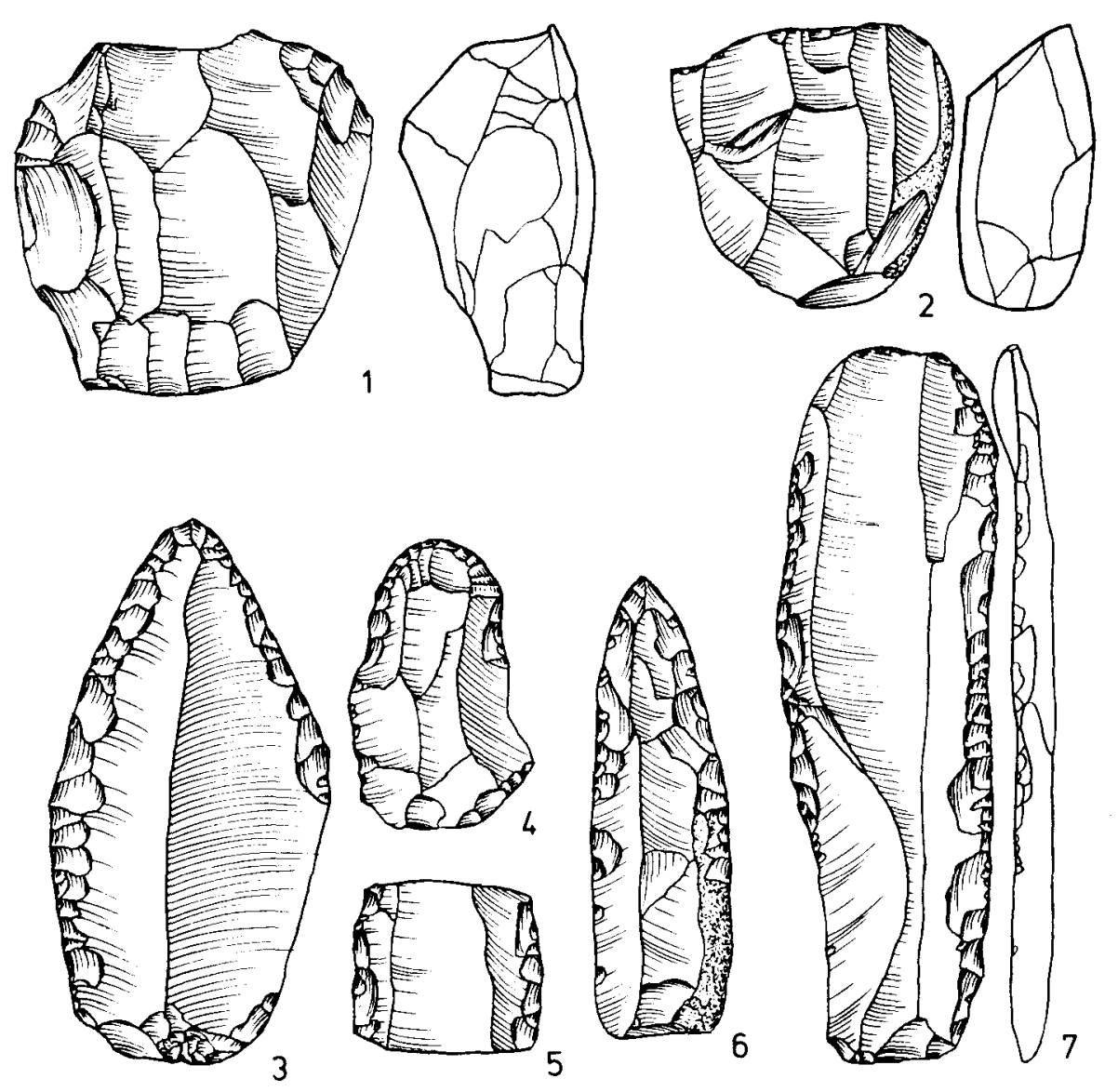

Fig. 5. Tolbaga, cerca de Tchita (Zabaikale, Siberia): 1 y 2 núcleos, 3 punta levalloisiense retocada, 4 raspador, 5 y 7 hojas retocadas, 6 hoja apuntada (según M. V. Konstantinov 1980).

carácter estrictamente local, diferente del de Europa y el Próximo Oriente.

2. Hay que buscar el origen de estos tecno-complejos en la tradición de los choppers cuyas raíces profundas están constatadas en el este y el sudeste asiáticos. Además, los descubrimientos recientes muestran que la técnica lamelar basada en los núcleos de tipo Gobi posee igualmente unas raices locales bastante profundas, 10 que está atestiguado por los utillajes de China, procedentes de Zhiyu, provincia de Shanxi, con sus dotaciones radiocarbónicas de aproximadamente $28.0000 \mathrm{BP}$. 


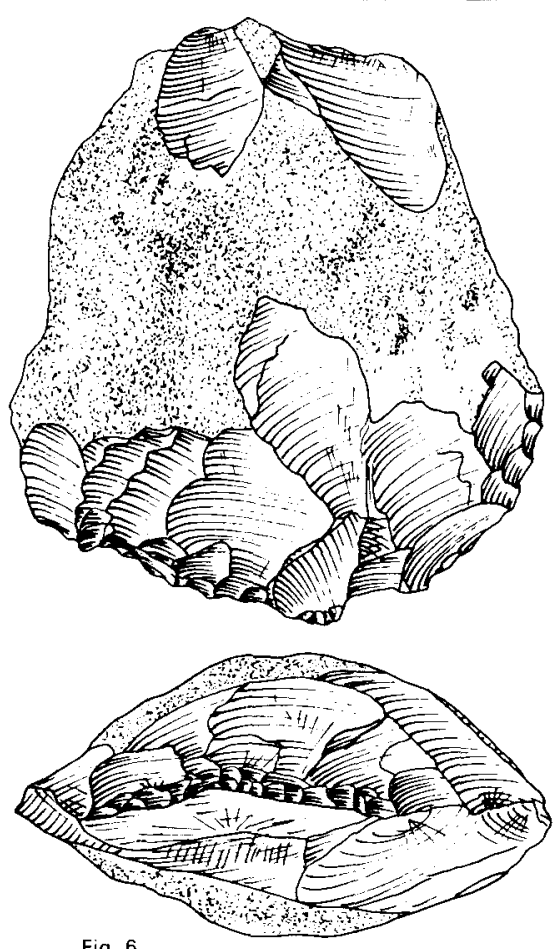

Fig. 6
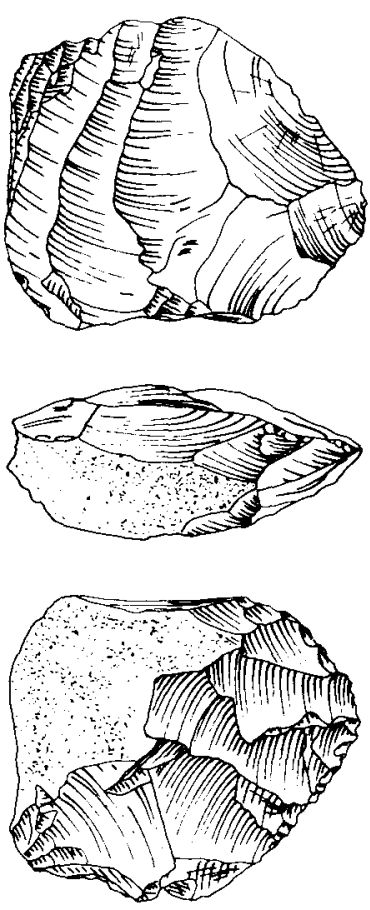

Fig. 7

Fig. 6. Osinovka (Primorie): chopper (segün A. P. Okladnikov 1959).

Fig. 7. Osinovka (Primorie): núcleo para hojas que evoca la preparación lavalloisiense (según A. P. Okladnikov 1959).

3. Sólo la técnica levalloisiense podria ser intrusiva en el Asia oriental, acaso debido a una influencia precedente del Medio Oriente a través del Asia central soviética y Mongolia.

4. Aunque el número de yacimientos sea ampliamente insuficiente, se puede, con todo, intentar distinguir las tendencias generales en la repartición geográfica de las más antiguas industrias del este de Siberia: tenemos en primer lugar los utillajes con choppers y con técnica laminar (incluida la de los núcleos Gobi) en las cuencas de los ríos Yenissei, Lena y Aldan; por otra parte en la cuenca del Angara existen los utillajes con técnica laminar de carácter esencialmente Paleolitico superior, sin núcleos de tipo Gobi. En el curso inferior del Amur y en Primorie existen los conjuntos con choppers y con la técnica levalloisiense; por el contrario, en el Pribaikale se encuentran sobre todo las industrias con técnica laminar y levalloisiense. 
5. En todo caso se puede constatar que, en el periodo que precede al Sartaniense, en el Asia oriental, la técnica bifacial y las puntas foliáceas aún no son conocidas. Esta constatación coincide con la situación existente en América en el mismo periodo.

\section{EL PROBLEMA DEL ORIGEN DE LOS ELEMENTOS FOLIÁCEOS BIFACES EN LA SIBERIA ORIENTAL}

Como ya hemos señalado, las puntas foliáceas no aparecen en Siberia hasta el periodo Sartan. Las más antiguas puntas de este tipo han sido encontradas en el valle del Aldan y se fechan entre 17.000 y $13.000 \mathrm{BP}$; proceden de los niveles profundos, IX y VIII, de la cueva Diouktaï, fechadas en ese momento por la interpolación de determinaciones radiométricas (Mochanov 1977).

El utillaje del nivel IX de la cueva Diouktaî sólo ha proporcionado 16 utensilios retocados, incluido un fragmento proximal de una punta foliácea con talla completamente bifacial. Entre los demás utensilios hay que notar la presencia de cinco hojas retocadas, un raspador, dos buriles y cinco hojitas con retoques finos. También deben citarse algunas plaquetas de silex con una talla parcialmente bifacial, que son probablemente piezas inacabadas de utensilios foliáceos (fig. 8).

En el nivel VIII de la misma cueva se encontraron 21 utensilios, incluidas siete puntas foliáceas, todas fragmentarias. Se trata de piezas bastante alargadas, poco gruesas, con retoque paralelo y de sección biconvexa. Además de las puntas foliáceas se constata la presencia de buriles (6), raspadores (3), raederas (2) y de hojitas con retoques finos.

En ambos niveles en cuestión, la técnica laminar está presente junto con la de lascas. Las puntas foliáceas han sido realizadas mediante retoque invadiente por presión, a la que se suma en ocasiones un retoque marginal más abrupto. En todo caso, estas piezas son bastante finas y no tienen nada que ver con los bifaces gruesos y toscos.

¿Acaso existen otros utillajes con puntas folláceas tan antiguos (de antes del $13.000 \mathrm{BP}$ ) en Siberia oriental? Hay que situar probablemente en el extremo comienzo del periodo Sartan una punta encontrada cerca del Hospital Militar de Irkutsk, aunque se trata de un hallazgo antiguo, del siglo pasado. Por tanto su contexto es desconocido.

Los demás utillajes con puntas foliáceas procedentes de las regiones de Pribaikale y Zabaikale, de las cuencas de los ríos Amur, Vitima, Olek- 

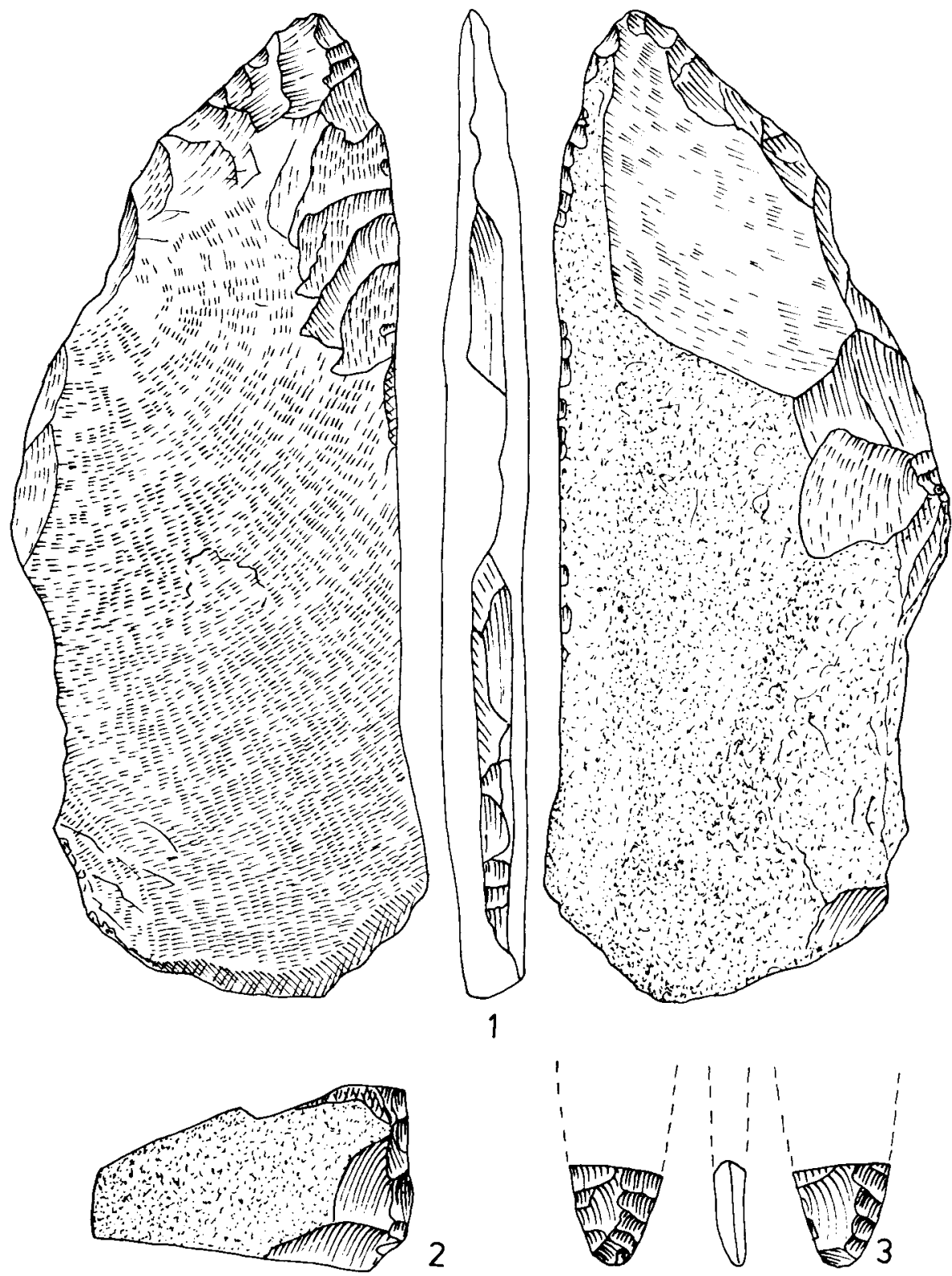

2

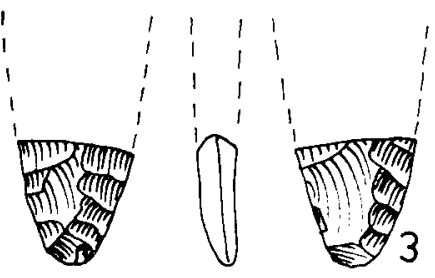

Fig. 8. Cueva de Diuktai (cuenca del Aldan, Siberia), Nivel IX: 1 y 2 plaquetas con talla bifacial (esbozos de puntas foliáceas), 3 fragmento proximal de una punta foliácea (según J. A. Mochanov 1977). 
ma e Indigirka, y del litoral del Pacífico (regiones de Primorie, Kamtchatka y mar de Okhotsk), datan probablemente de periodos más recientes, sobre todo del Sartaniense reciente y del final del Pleistoceno.

La posición cronológica de las más antiguas puntas foliáceas en el Japón es bastante incierta (fig. 10). Las puntas que alli se encuentran hacia el $20.000 \mathrm{BP}$ son únicamente de cara plana, hechas sobre lascas o sobre hojas (MORLAN 1971). Las piezas completamente bifaciales, que evocan los primeros ejemplares siberianos, como por ejemplo las puntas de Uenodaire, no aparecen hasta más tarde y, además, son bastante raras en las islas japonesas. Las puntas pedunculadas son aún más tardias, fechándose sobre todo en el Holoceno.

Por el contrario, en Siberia las puntas pedunculadas bastante especializadas y bien desarrolladas aparecen pronto, pudiéndose fechar, en el nivel VIl de la base de la sección del yacimiento de Ouchkj (Kamtchatka) en un tiempo situado entre 13.600 y 14.300 BP (fig. 9).

Por tanto hay que tener en cuenta la posibilidad de que en el extremo nordeste de Asia existiesen ya desde este periodo las industrias con diferentes puntas foliáceas que podrian derivar de un fondo común. Estas industrias son parcialmente inaccesibles puesto que cubrian también la zona del Shelf continental al este del litoral del Pacifico durante la recesión correspondiente al Sartaniense.

El origen de las puntas foliáceas del Asia oriental ha sido objeto de dos discutidas hipótesis. La primera quiere que las puntas deriven de los bifaces achelenses, aunque a esta afiliación se oponen dos argumentos:

1. En Asia oriental la presencia de los bifaces achelenses no ha sido confirmada de forma indiscutible. Contrariamente a la opinión emitida por Laritchev (1976) y Okladnikov (1978), no podemos considerar los proto-hand-adzes de Dingtsun como verdaderos bifaces, y las demás piezas mencionadas por dichos autores, en especial de China y de Mongolia (Monte Yarkh), no están publicadas de forma suficiente para atestiguar su carácter achelense.

2. En Asia oriental no existen formas transitorias entre los bifaces achelenses y las puntas foliáceas con retoque invadiente plano.

Ante esta situación hay que examinar la otra hipótesis que admite el origen occidental de las puntas foliáceas asiáticas. Hay que subrayar en primer lugar que en el periodo de la formación de las culturas del Paleolítico superior asiático una sensible influencia del Levolloiso-Musteriense se puso de manifiesto en el Asia centro-oriental. Probablemente esta influencia llega desde el Próximo y el Medio Oriente a través del Cáucaso 

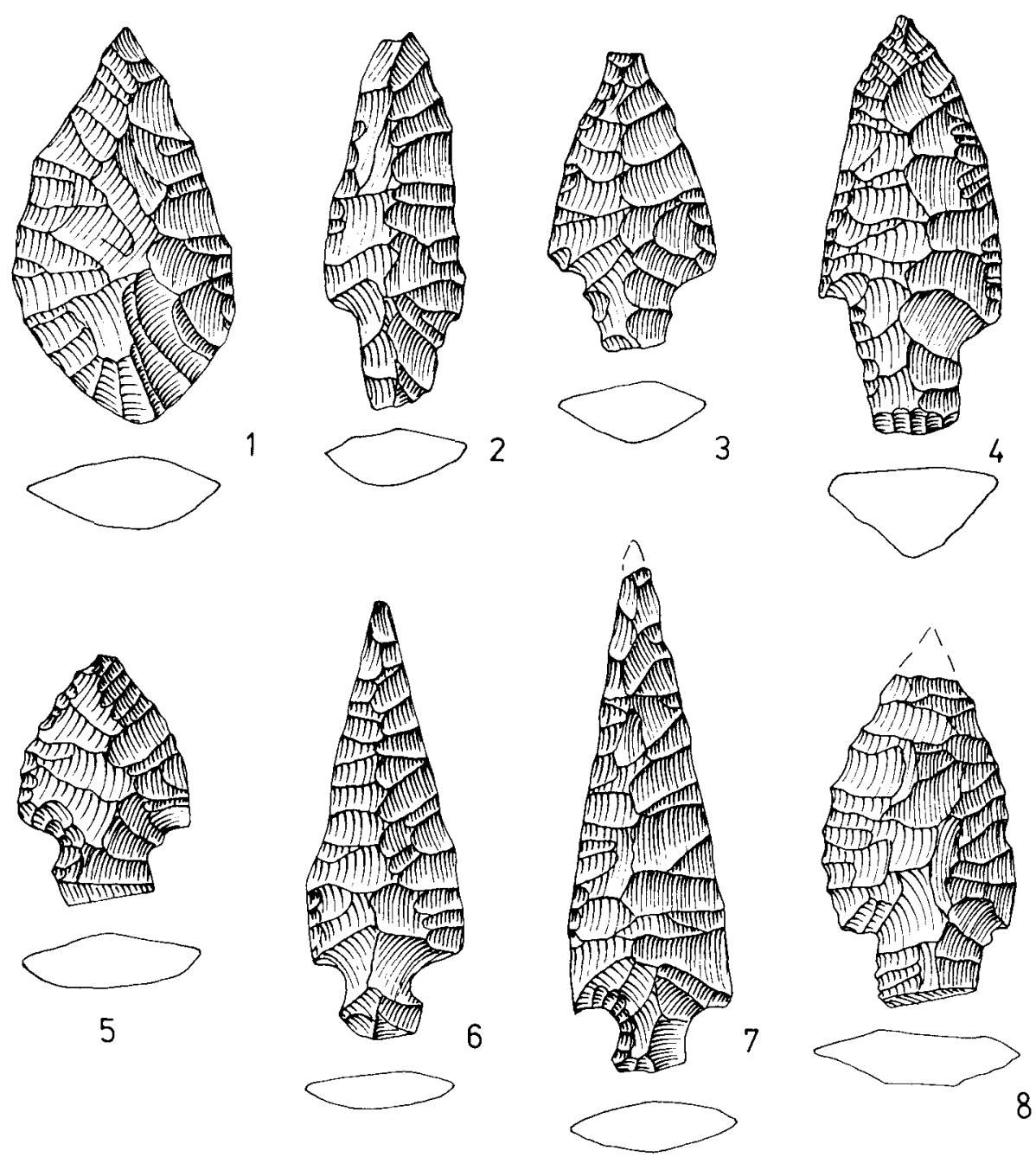

Fig. 9. Uchki I (Kamtchatka), nivel VII: 1 a 8 puntas foliáceas (según N. N. Dikov 1977), $1: 1$

y del Asia central soviética. En el Levalloiso-Musteriense de esta zona, en particular en las regiones cercanas al Mar Negro, aparecen las puntas foliáceas. La presencia de estos utensilios en el mismo contexto ha sido recientemente señalada para el Kazajstan, en la península de Mangyshlak sobre el lago de Abkhash (Medoev 1972). Por tanto es muy probable que 
las puntas foliáceas pudiesen aparecer en los conjuntos Levalloiso-Musterienses aún más al este, en particular en la zona meridional de la Siberia oriental.

\section{LAS INDUSTRIAS PRE-CLOVIS CON PUNTAS FOLIÁCEAS BIFACIALES EN EL NUEVO MUNDO}

De nuestra crítica de las fuentes arqueológicas para la Prehistoria del Nuevo Mundo resulta que las puntas foliáceas no aparecen alli antes del $16.000 / 15.000 \mathrm{BP}$. Parece que las más antiguas puntas foliáceas forman en América, en el vasto territorio entre los Estados Unidos y el Perú, un horizonte cronológico bastante restringido, entre 16.000/15.000 BP, por tanto apenas más reciente que las más antiguas puntas foliáceas de la Siberia oriental. Esta correlación cronológica aunque muy interesante no proporciona un argumento decisivo para explicar el origen de las puntas americanas.

Las más antiguas puntas foliáceas de América son bastante diferenciadas desde el punto de vista tipológico, pero desde el punto de vista tecnológico forman dos grupos:

1. las talladas por percusión directa y realizadas alternativamente primero sobre el borde de una cara y luego sobre el borde opuesta de la otra cara. De la aplicación de esta técnica resultan las puntas con sección romboidal;

2. las talladas más bien por presión, pero a veces también por técnica esquirlada, realizados simultáneamente sobre los dos bordes y sobre las dos caras. Las puntas obtenidas mediante esta técnica se caracterizan por una sección biconvexa simétrica.

El primer grupo comprende las puntas de tipo El Jobo, fechadas en Taima Taima (Venezuela) de 14.010 BP, y las más antiguas puntas de los Andes del Perú, encontradas en el complejo Ayacucho de la cueva Pikimachay (fig. 12). Al segundo grupo hay que atribuir las más antiguas puntas de América del Norte, encontradas en el nivel lla del Abrigo Meadowcroft (Pennsylvania) (Adovasıo 1978), fechadas en el 14.225 BP (fig. 11).

Si las piezas del primer grupo (tipo El Jobo) son más bien alargadas y estrechas, con una base puntiaguda, las puntas del segundo grupo (tipo Meadowcroft) son triangulares, más anchas, con la base casi rectilinea. 

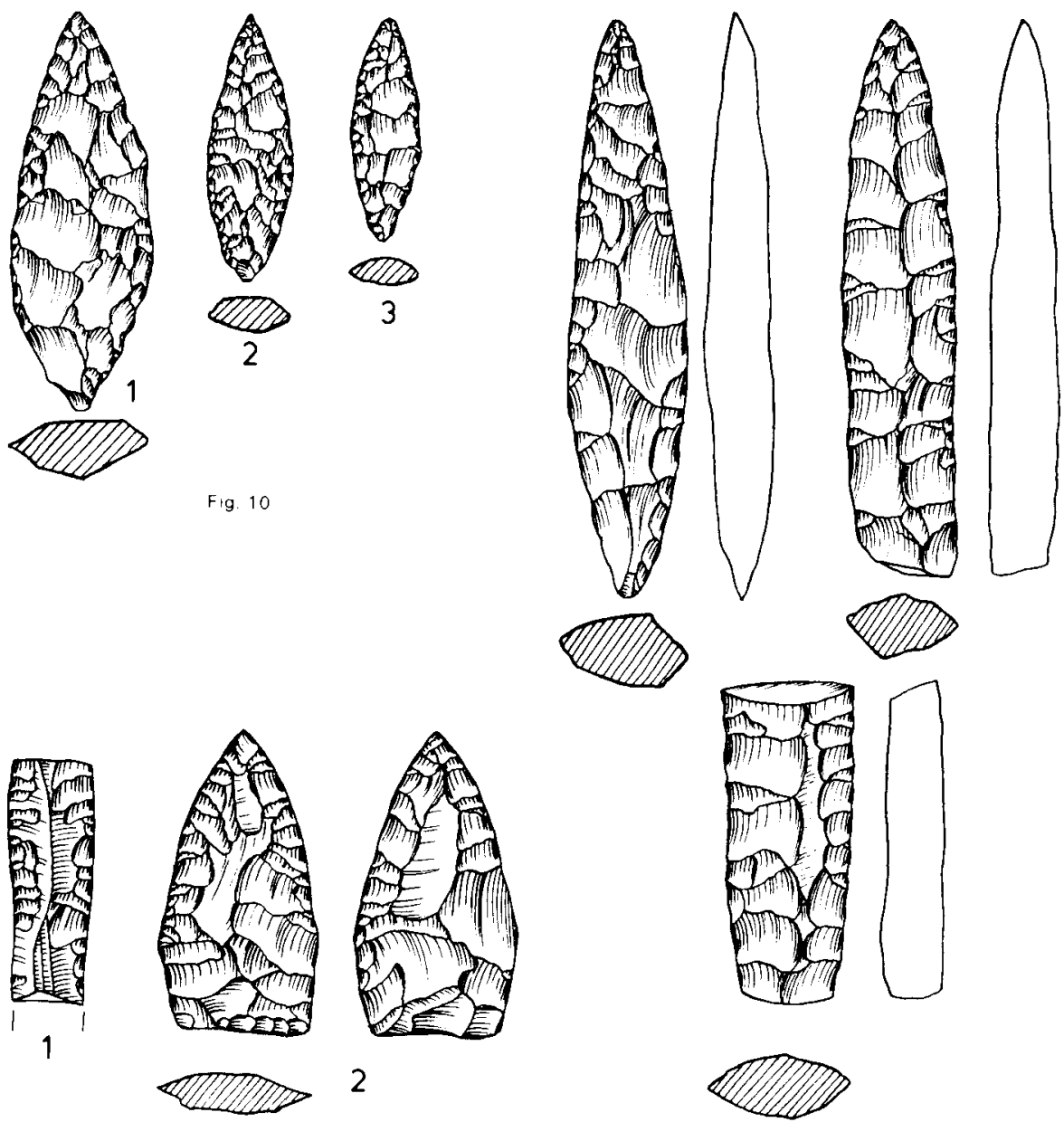

2

Fig. 11

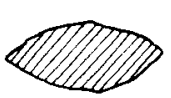

Fig. 12

Fig. 10. Uenodaire (Japón): 1 a 3 puntas foliáceas (segin J. Morlan 1971), 1:1

Fig. 11. Meadowcroft Rockshelter (Pennsylvania), nivel Ila: 1 hoja retocada, 2 punta foliácea bifacial (según J. Adovasio 1978), 1:1

Fig. 12. Puntas de El Jobo (Venezuela). Colección A. Bryan, 1:1.

El primer grupo comprende asimismo la punta ya mencionada del yacimiento mexicano de Tlapacoya I.

El contexto lítico que acompaña las más antiguas puntas americanas 
es también bastante diferenciado. Las puntas de El Jobo se encuentran, si se admite la homogeneidad de los conjuntos publicados por J. Cruxent (1956), con un rico surtido de raederas, parcialmente con retoques invadientes. Las puntas foliáceas de Ayacucho, en los Andes del Perú, aparecen acompañadas por un contexto laminar, probablemente más antiguo, dado que una hoja retocada muy fina procede del nivel más antiguo del abrigo Meadowcroft, fechado en 17.650/17.150 BP (AdovasIo 1978).

En relación con el tema de las más antiguas puntas americanas, hay que discutir aqui la hipótesis de Alan Bryan (1978) que quiere interpretar la secuencia de los utillajes pre-foliáceos, que precederian a los de las puntas foliáceas, en los términos de una evolución local que tuvo lugar en la misma América. Para reforzar su hipótesis, Bryan evoca el ejemplo del Solutrense en Europa que le parece deriva de un medio local perigordiense sin piezas foliáceas. Esta argumentación no nos parece muy convincente puesto que las investigaciones recientes nos llevan a la conclusión que hay que buscar el origen del Protosolutrense en las industrias con puntas de cara plana y con puntas foliáceas de la Plaine du Nord, y los descubrimientos recientes de Bélgica y de la Gran Bretaña confirman esta suposición. Una técnica tan sofisticada como la del retoque solutrense, al igual que la de las puntas americanas, no podria resultar más que de una evolución larga para la que hay que buscar las raices en el Paleolitico medio. En el estado actual de nuestro conocimiento del problema, esta evolucion de las puntas americanas, tendria que haber tenido lugar fuera de América, probablemente en Asia, aunque sus origenes, como hemos indicado en el parágrafo precedente, remontan también al Paleolítico medio de las regiones más occidentales.

La justificación detallada de nuestra posición y la reconstrucción exacta del proceso de aparición de las primeras puntas foliáceas en América presenta, sin embargo, ciertas dificultades:

1. La intrusión de los portadores de estas puntas de Asia a América a través de Beringia es fácilmente admisible en el XVI milenio BP, pero su paso por el corredor continental entre los glaciares cordilleranos y laurentianos parece que tendria que ir acompañada de una retirada glacial en este periodo. Aunque ciertos autores lo admiten como más tardío (13.000 BP), las condiciones climáticas del interestadio de Eri no excluyen esta posibilidad.

2. El estado actual de nuestra investigación no nos permite indicar un antecedente asiático directo para las industrias americanas con puntas foliáceas. Es seguro que existe una próxima analogía entre la técnica de talla de las puntas de Diouktaï y las de El Jobo, pero 
el contexto lítico es diferente. Por ejemplo, en los utillajes asiáticos con puntas foliáceas, las hojitas obtenidas de los núcleos de tipo Gobi están casi siempre presentes, mientras que esta técnica falta por completo en el contexto de las más antiguas puntas americanas. Con todo, hay que recordar que se conocen, en el litoral del mar de Okhotsk, unos utillajes, como Khoukhtouï III (Mochanov 1978), en los que las puntas foliáceas aparecen en un contexto laminar (incluyendo hojas y lascas con retoques marginales), pero sin núcleos en quilla del tipo gobiense. Las puntas encontradas en Khoukhtouil se parecen, desde el punto de vista técnico, a ciertas piezas foliáceas americanas, pero, desgraciadamente, su posición cronológica es desconocida; por ello no pueden servir como induscutibles antecedentes de las puntas americanas (fig. 13).

En resumen, nos oponemos a la hipótesis de Alan Bryan (1978) puesto que no encontramos ningún argumento positivo que atestigue el origen local de las puntas americanas, aunque en el estado actual de nuestro conocimiento del problema, no podamos señalar los antepasados directos de las más antiguas puntas foliáceas americanas. Pensamos que es altamente probable que la investigación futura, en particular en el litoral asiático del Pacifico, pondrá en evidencia las industrias con afinidades directas hacia las puntas americanas.

Por último, hay que mencionar la opinión de Müller-Beck (1969) que quiere buscar el origen de las puntas americanas en las del tipo de Sungir, conocidas en el Paleolítico superior antiguo de la Europa oriental, y que se pueden fechar entre el periodo de Aray-Stillfried B y el de Lascaux. Esta hipótesis, aunque posible en el aspecto tecnológico, no nos parece justificada a causa del gran hiatus territorial que separa las puntas de Sungir, siempre al oeste del Ural, de las de tipo Clovis en América del Norte. Sobre este vasto territorio que incluye toda Siberia no se ha señalado ninguna punta de tipo Sungir, como tampoco ningún conjunto lítico análogo a la industria de Kostienki-Sungir. No hay ninguna razón para contemplar como más probable la afiliación entre las puntas americanas y las de Sungir, como no la hay entre aquellas y las solutrenses (SMITH 1962).

\section{GENESIS DE LAS INDUSTRIAS DE PUNTAS FOLIÁCEAS CON TÉCNICA DE ACANALADO}

El problema de la aparición de las puntas foliáceas en el Nuevo Mundo, discutido en el epigrafe precedente, nos lleva a otra cuestión: el per- 

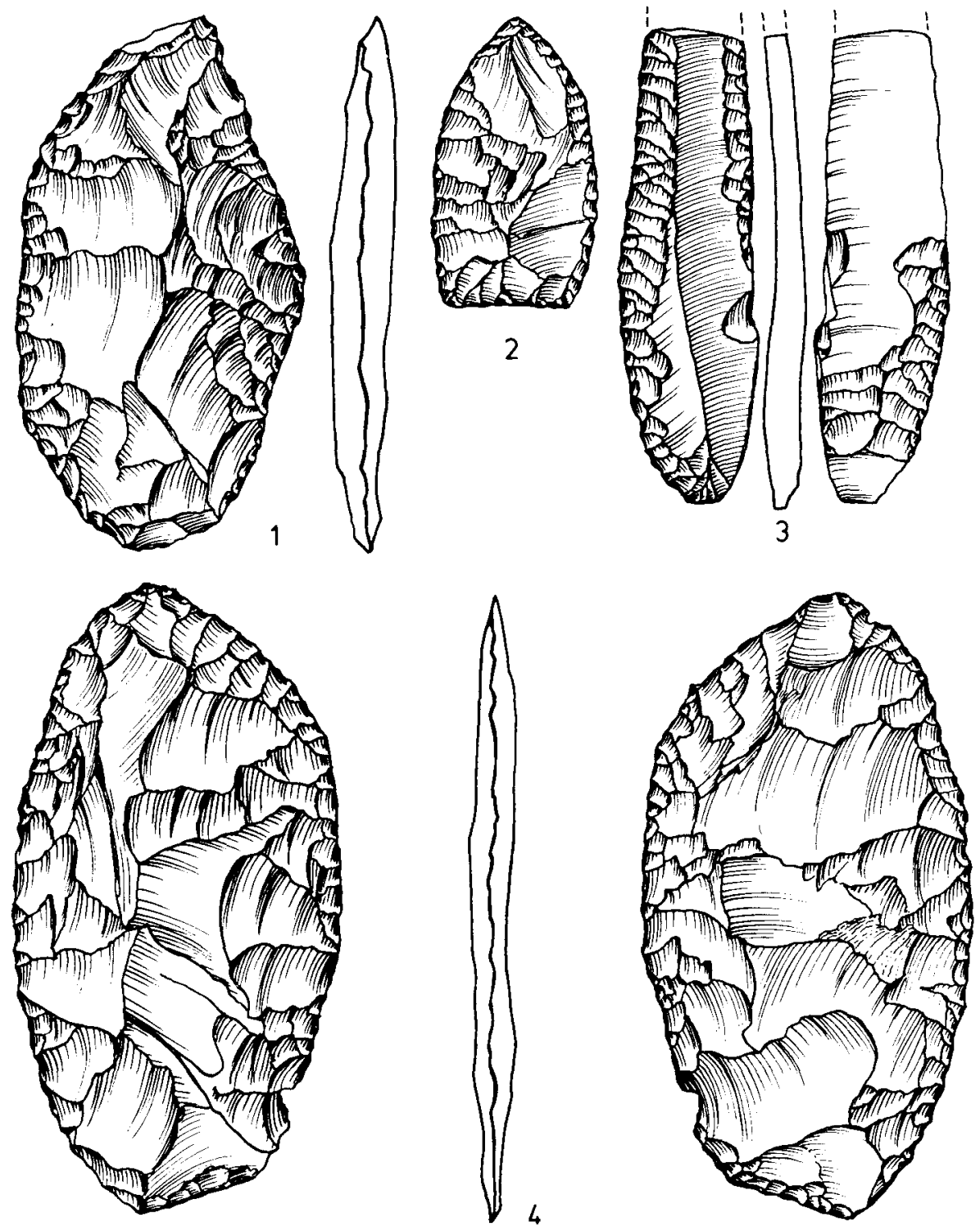

Fig. 13 Kukhtui (Primorie): 1 a 4 puntas foliáceas (según J. A. Mochanov 1978), $1: 1$. 
feccionamiento de las puntas foliáceas y la aparición de las acanaladas en el contexto paleo-indio. Estas puntas son caracteristicas de las industrias liticas de las culturas de cazadores especializados, recordando lo que se encuentra en el Viejo Mundo durante el Pleistoceno reciente en los medios del Paleolítico superior. Por tanto se plantea de nuevo la cuestión de saber si esta especialización, incluido el desarrollo de las puntas que estamos tratando, se debe a una intrusión original del Viejo Mundo o si debemos pensar en una evolución independiente en América. Antaño, la cultura de Sandia, cuya datación en torno a 20.000 BP o incluso antes es más que insegura (la relación entre los restos culturales y las muestras de la Sandia Cave, New México, fechadas por C14, no es segura), era considerada como antecedente de la cultura de Clovis. Las «puntas Sandía" están retocadas en sus dos caras y a veces tienen una silueta curvilínea y otras unos bordes más o menos rectilineos; muchas de ellas tienen una muesca lateral, pero no un acanalado. Tal acanalado, aplicado a la base de la punta después de que ésta hubiera sido retocada cuidadosamente en toda la superficie y destinada al enmangue, es característica de las puntas de la cultura de Clovis o más bien del complejo de Llano, fechado - no sin reservas- en el periodo entre 12.000 y 11.000 $\mathrm{BP}$, o incluso más tarde. La estratigrafía de la Sandia Cave no atestigua la sucesión de puntas Clovis después de las de Sandia, dado que los dos tipos aparecen en el mismo nivel. Por tanto, es probable que las puntas de Sandia coexistiesen con las puntas de Clovis, lo que hace pensar que ambas derivan de un fondo común acaso representado por las puntas del tipo Meadowcroft. El acanalado está extremadamente desarrollado en las puntas de la cultura de Folsom que, cronológicamente, puede situarse entre 11.000 y 10.000 BP. Si hacemos abstracción de las puntas de Sandia, cuya datación es todavia muy insegura, y si tenemos en cuenta en particular el fenómeno del acanalado tan inhabitual por lo general como típico para el complejo de Llano, la cultura de Folsom y las variantes sucesivas de las puntas del medio paleo-indio, es más verosímil que nos encontremos ante una evolución que ha tenido lugar en la parte meridional de América del Norte. Además, una génesis autóctona es incluso más probable por el hecho que el desarrollo de las culturas paleo-indias, caracterizadas por las puntas con acanalado, se produjo durante el periodo en que las regiones correspondientes estaban aisladas de Beringia por el hielo. De tal modo que la única vía por la que elementos nuevos habrían podido llegar a Asia y América hacia el final del Pleistoceno estaba bloqueada. Por otra parte, como ya hemos dicho, no existe ninguna evidencia de que la invención de la técnica del acanalado tenga sus raices en el Viejo Mundo. Si, excepcionalmente, se encuentran puntas acanaladas en las regiones más septentrionales de América -como la de tipo Fol- 
som de la región del rio Utukok en Alaska del noroeste, publicada por $\mathrm{R}$. Solecki (1951, pag. 484) - creemos que se trata muy probablemente de elementos que marcan un movimiento hacia atrás efectuado por grupos paleo-indios cuando el corredor en el hielo, mencionado en el epigrafe 4, permitió a los animales y al hombre retroceder hacia el norte.

\section{EL DESARROLLO CULTURAL DEL NORDESTE DE ASIA ENTRE $17 / 15.000$ Y $11.000 \mathrm{BP}$}

La mayoria de las tradiciones tecnológicas constatadas antes de $17 /$ 15.000 BP prosiguieron su desarrollo durante el periodo del Sartan reciente, incluidos los interestadios de Mamontovo y Kokorievo. Esto se refiere sobre todo a las industrias con puntas foliáceas, que, en esta época se hacen más diferenciadas y aumentan considerablemente su zona de repartición.

En el cuadro de las industrias foliáceas, es particularmente la cultura de Diouktai la que prosigue su desarrollo en la cuenca del Aldan. El nivel medio (VII) de la cueva Diouktaï está fechado entre 14.000 y $12.690 \mathrm{BP}$. EI utillaje de este estrato es bastante pobre, pero sigue conteniendo los mismos elementos técnicos y tipológicos (fig. 14). La técnica de la producción de hojitas a partir de los núcleos de tipo gobiense es utilizada y acompaña a las demás técnicas laminares. Entre los utensilios retocados, los buriles, los raspadores y las hojitas con retoques finos son los más numerosos. En el grupo de las puntas foliáceas aparecen ejemplares grandes, de hasta $13,5 \mathrm{~cm}$ de longitud. Son de sección oval o romboidal, su forma es más bien alargada y la base es puntiaguda. Durante este periodo la cultura de Diouktaï avanza aún más hacia el norte, alcanzando la cuenca del Kolyma (por ejemplo el yacimiento de Mayorytch; MocHanOV 1977).

Otra entidad con puntas foliáceas está representada en Kamtchatka por el nivel inferior (VII) del yacimiento I en las orillas del lago Ouchki, fechado entre 14.300 y 13.600 BP. También aqui la técnica es laminar (fig. 15). El tipo de núcleo más común es de tipo cilindrico, acompañado por algunos núcleos con dos planos de percusión opuestos o bien por los núcleos con preparación bilateral que evocan los núcleos Levallois. Los núcleos gobienses son menos caracteristicos, aunque están presentes los restos de talla de su preparación y explotación. Los utensilios retocados están representados principalmente por raederas laterales y transversales, a veces dobies, y por los raspadores. Las puntas foliáceas son nu- 

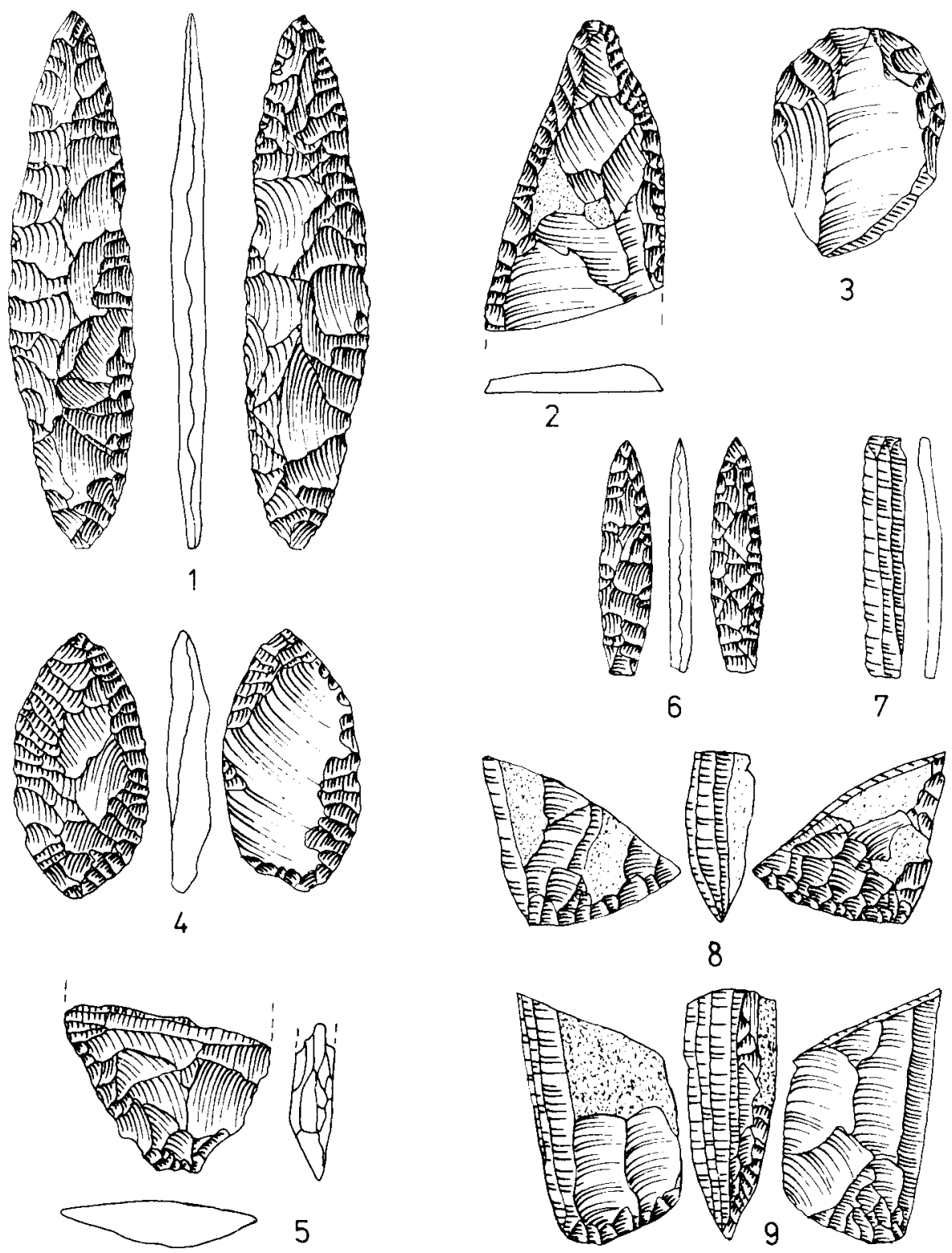

Fig. 14. La cueva de Diuktai (cuenca del Aldan, Siberia), niveles VIIb (1-3) y VIla (4-9): 1, 4, 5, 6 puntas foliáceas, 2 punta de cara plana, 3 raspador, 7 hojita, 8 y 9 núcleos de hojitas del tipo Gobi (según J. A. Mochanov 1977). 

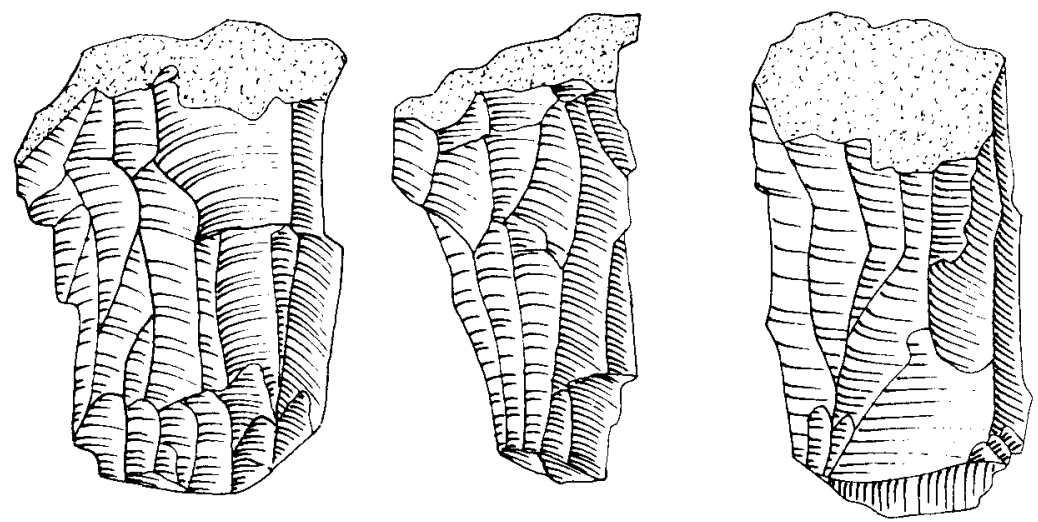

1
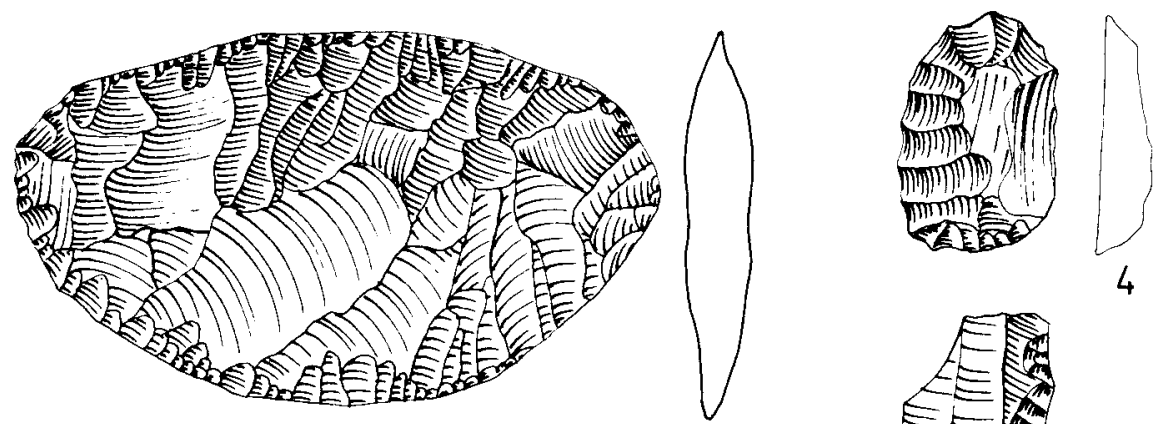

2
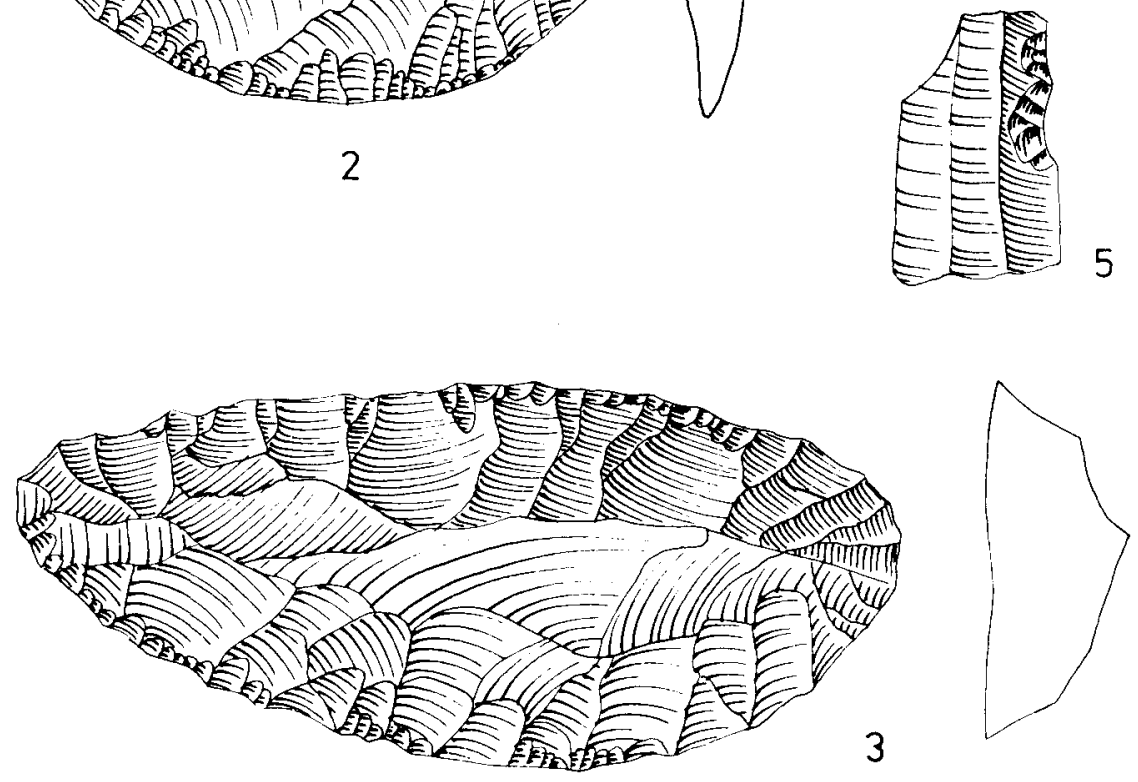

Fig. 15. Uchki (Kamtchatka), nivel VII: 1 núcleo de hojas con dos planos de percusión opuestos, 2, 3 raederas transversales dobles, 4 raspador, 5 hoja con escotaduras (según N. N. Dikov 1977). 
merosas y bastante diferenciadas, incluyendo sobre todo ejemplares pedunculados; sus dimensiones son bastante variables, pero más bien pequeñas, su sección es biconvexa o subtriangular.

A nuestro parecer las culturas de Diouktaï y de Ouchki derivan de tradiciones tecnológicas diferentes, aunque contienen ciertos elementos comunes, en particular en la técnica de producción de los soportes líticos. Hay que esperar que fases más antiguas serán identificadas asimismo para la cultura de Ouchki, del mismo modo que las que conocemos actualmente para la cultura de Diouktaï. En este punto no seguiremos la idea de Dikov (1977) que supone que la aparición de las puntas pedunculadas en Kamtchatka va unida a un movimiento de retroceso de los grupos humanos de América a través de Beringia. Los argumentos paleoecológicos y paleo-geográficos se oponen a esta hipótesis, al igual que la situación cultural en el litoral del noroeste de América (BORDEN 1975) y la distribución cronológica y territorial de las más antiguas puntas pedunculadas americanas.

Paralelamente con las industrias de puntas foliáceas se conocen igualmente en el nordeste de Asia las industrias con hojas y con lascas, sin elementos foliáceos bifaciales. En este marco se sitúa la continuación de la cultura de Afontova Gora, cuya fase reciente se fecha en el XIV y XIII milenios BP (Tashtik a orillas del Yeniseï; 12.180 BP, Kokorievo II; 13.300 BP, Kokorievo III). Estos conjuntos siguen conteniendo choppers (7\% de media), raederas (34-45\%), raspadores (19-26\%), piezas esquirladas (8$23 \%$ ) y las hojitas con retoques finos (3-6\%) (ABRAMOva 1979).

Para este periodo existen elementos similares en el sur del lago Baikal, formando la cultura llamada de Selenga (ABRAMova 1978), caracterizada por los choppers, la técnica lamelar con núcleos gobienses $y$, en algunos lugares, también por la técnica esquirlada. Tenemos que señalar que en esta entidad la tasa de elementos arcaicos, musteroides, es considerablemente más elevada, puesto que aparecen aqui las puntas, las raederas convergentes, las raederas-cuchillo bifaces y los demás utensilios sobre lascas. Estas últimas se obtienen a partir de núcleos sobre cantos, con dos planos de percusión opuestos, sin preparación.

Los conjuntos industriales que contienen choppers, núcleos para hojitas de tipo gobiense y utensilios como raspadores, raederas, buriles y piezas con muesca se conocen asimismo en el Extremo Oriente soviético, sobre todo en Primorie. Estos conjuntos en la fase más antigua, situada en Oustinovka en un suelo interestadial del Sartaniense reciente, todavia no contienen las puntas foliáceas, que sólo aparecen en la fase más avanzada, en el mismo sitio en un souglinok (limo) subyacente. Los elementos similares, incluidos los núcleos de hojitas del tipo gobiense, a los que se 
suman las hojas y las truncaturas retocadas tipicas, son conocidos en la isla Sakhalin (yacimientos: Imtchin I y Takoye II), donde ya son sensibles ciertas afinidades con las islas japonesas. Desgraciadamente la edad exacta de estos yacimientos es desconocida, si bien parecen situarse en el Sartaniense reciente (VASILEVSKIY 1979).

De forma simultánea con las entidades hasta aqui mencionadas, aparecen en Siberia las industrias con técnica lamelar gobiense, pero sin choppers (o con choppers muy raros). Su representante más caracteristico es la cultura de Kokorievo, fechada entre 15.460 (Kokorievo IV) y 11.600 BP (Novoselovo). Las industrias de esta cultura incluyen sobre todo raspadores, hojas retocadas y hojas con el extremo adelgazado mediante un retoque esquirlado.

Entre las demás culturas de Siberia hay que mencionar la posibilidad de la continuación durante este periodo del desarrollo de la cultura de Malta-Bouret'. Lamentablemente, esta posibilidad no está confirmada por evidencias geocronológicas indiscutibles, aunque el yacimiento de Akhinska, cerca de Tomsk, parece datar del Sartaniense reciente, e incluye la técnica laminar de tipo Malta, asi como numerosas hojas retocadas, perforadores y raspadores (ANIKOVITCH 1976).

El panorama del desarrollo cultural en Siberia durante el Sartaniense reciente parece confirmar la continuación de todas las tradiciones esenciales establecidas durante el periodo precedente. La diferenciación cultural en este periodo es el resultado de interferencias o de una evolución divergente de tradiciones más antiguas. En principio no observamos ninguna nueva intrusión halógena. Si bien en Siberia existen elementos cuyo origen es incierto, no parecen derivar, al menos en el estado actual de nuestro conocimiento del problema, de territorios cercanos. Podemos constatar, por tanto, el desarrollo local de la Siberia oriental durante el Sartaniense reciente, hasta el momento en que con los cambios de la fauna los grupos de cazadores de mamuts del Paleolítico superior tienen que sufrir una adaptación a las nuevas condiciones ecológicas, especializándose sobre todo en la caza del reno.

\section{PRIMERAS INDUSTRIAS EN EL NOROESTE DE AMÉRICA}

Aunque nuestros conocimientos respecto a la situación cultural en Alaska en los tiempos finales del Pleistoceno sean todavia muy limitados, lo que si se puede observar es que la evolución en Siberia entre 17/15.000 y $10.000 \mathrm{BP}$ ha influido sobre aquella en relación con nuevas inmigracio- 
nes. En todo caso, la estratigrafía del yacimiento de Onion Portage (curso medio del Kobuk, Alaska del noroeste), es muy instructiva. El lugar fue descubierto por J. Louis Giddings y luego excavado principalmente por Douglas D. Anderson (1968, 1970). En la base de ocho estratos arqueológicos -desde 8.500/8.000 BP hasta el siglo XVII de nuestra era- se encontró el complejo de Akmak. Esta industria es anterior al 8.500/8.000 BP y, según Anderson, podría remontar hasta 13.000 BP. James Dixon (1975, pág. 70) ha dado a conocer una fecha de C14: $9.570 \pm 150 \mathrm{BP}$. El complejo industrial tiene dos componentes: uno macrolítico y otro microlítico. El primero incluye artefactos que recuerdan los de una industria con bifaces foliáceos y untensilios trabajados sobre hojas; el segundo está caracterizado por minúsculas hojitas, obtenidas de núcleos de tipo Gobi (figs. 16 y 17). Anderson reúne este complejo de Amak con el complejo de Kobuk - directamente superpuesto y fechable hacia finales del VII milenio BP- bajo la denominación general de «tradición paleo-ártica americana». Supone que su origen está en el Viejo Mundo: “En Asia, las industrias que tienen las mayores semejanzas con Akmak no se encuentran en las regiones próximas a Alaska, sino a una distancia de 3.000 millas, alrededor del Lago Baikal. Los elementos especialmente emparentados son los grandes bifaces sobre núcleo y la técnica especifica de manufactura de hojas. Otras formas de Akmak, como el buril sobre truncatura retocada, los cuchillos bifaces y los pulidores en gres, existen en la región del lago Baikal, pero se hallan también por una parte por toda el Asia septentrional y por otra en América. Los núcleos delgados, en forma de quilla, con una larga historia de desarrollo alrededor del Pacifico, acaso tienen un origen diferente de los demás elementos ya discutidos" (ANDERSon 1970, pág. 70).

En lo que se refiere al origen asiático del complejo de Akmak, las analogias indicadas por Anderson son poco precisas. Tal como hemos subrayado en el epigrafe precedente, en el nordeste de Siberia existe una cultura que comporta los mismos elementos - piezas bifaciales, hojas, hojitas obtenidas de núcleos de tipo Gobi- que es la cultura de Douktaï. Su edad, anterior a Akmak, confirma la hipótesis de un parentesco más o menos directo. Por tanto que consideran una nueva migración a través de Beringia, poco antes de que el puente terrestre fuese interrumpido definitivamente y sustituido por el estrecho de Bering.

Es lamentable que sean muy poco conocidas las excavaciones que John Cook llevó a cabo desde 1967 en otro yacimiento estratificado, Hilay Lake, a $125 \mathrm{~km}$ al sur de Fairbanks, en la Alaska central. Al parecer el complejo de Chindadu, localizado en la base de dicha estratigrafia y fechado por el radiocarbono entre 8.000 y 10.500 (11.000?) BP, podría tam- 


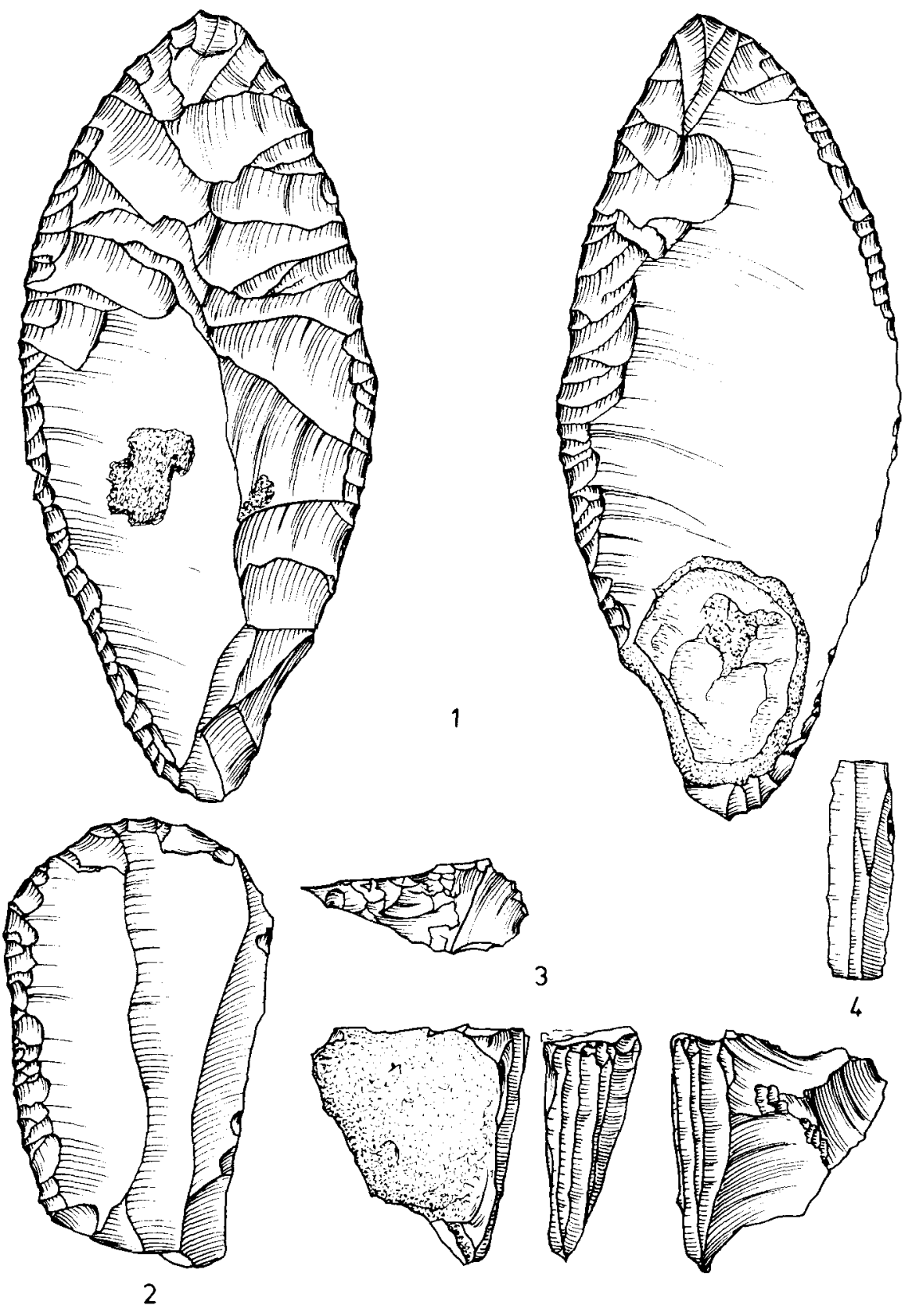

Fig. 16. Akmak (Onion Portage, Alaska): 1 punta de cara plana, 2 raspador, 3 núcleo de tipo Gobi, 4 hojita (según D. D. Anderson 1970). 


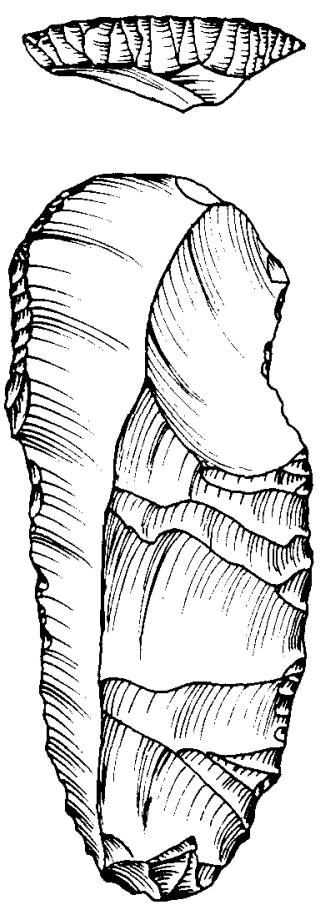

1

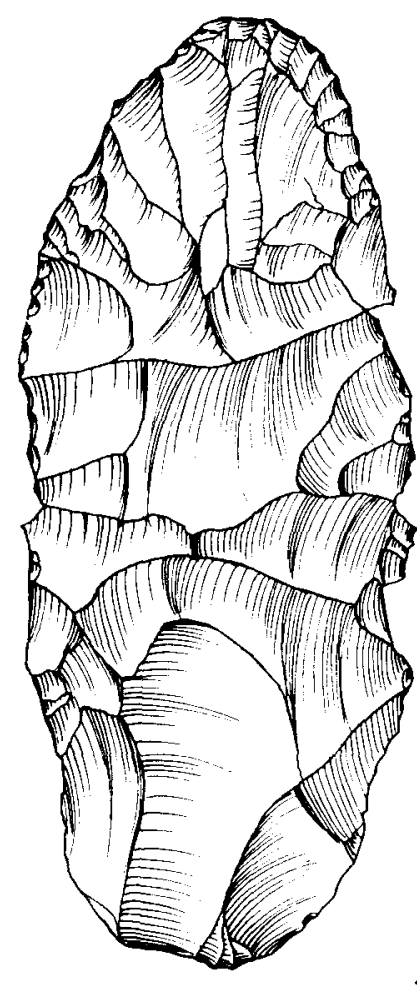

2

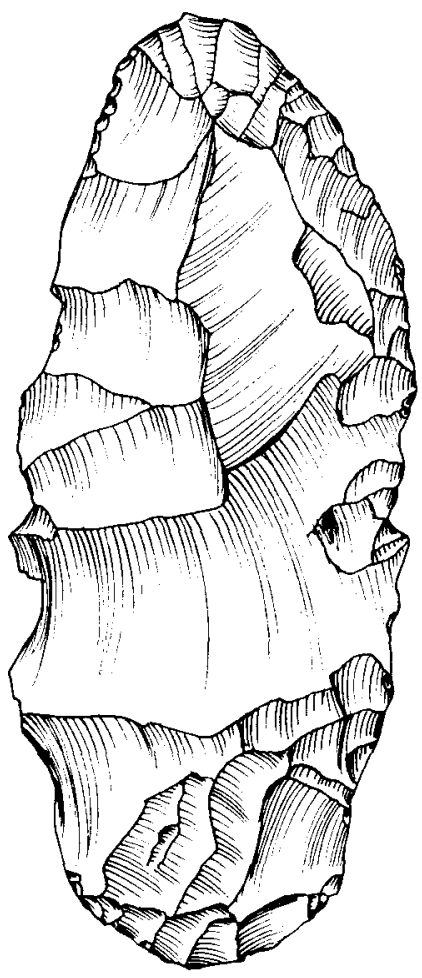

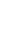

Fig. 17. Akmak (Onion Portage, Alaska): 1 raspador, 2 punta (?) bifacial (según D. D. Anderson 1970).

bién ser importante para el tema de la inmigración que aqui discutimos (Dixon 1975, pág. 71).

En lo que se refiere al desarrollo sucesivo en América del noroeste, podemos constatar lo siguiente: Anderson no ve prácticamente un rasgo común entre Akmak y las industrias de hojas como la de Anangoula, de la que hablaremos en el epigrafe 13. Por el contrario, piensa que hay evidentes relaciones entre Akmak y el complejo de Denali, es decir, que ambos pueden ser incluidos en la tradición paleo-ártica americana.

Fred Hadleigh-West, basándose en el material lítico, ha definido el complejo de Denali -que incluye el famoso Campus Site, cerca de Fairbanks - de la forma siguiente (HADLEIGH-WEST 1967): los núcleos en forma de quilla, destinados a la fabricación de hojitas microliticas obtenidas sólo sobre un lado, son especialmente caracteristicas; buriles sobre lasca, con 
frecuencia múltiples; bifaces, probablemente usados como cuchillos; raspadores sobre lasca, en general bastante anchas; hojas largas, etc. (fig. 18). En lo que concierne a la datación del complejo de Denali, HadleighWest (1967, pág. 378) ha señalado como estimación el periodo de 13.000 a $8.000 \mathrm{BP}$. Despues, este autor ha estudiado el problema con más detalle (HADLEIGHT-WESt, en prensa). Propone ver el complejo de Denali como la rama oriental de una Beringia Tradition, cuyo centro habria estado en la región del puente terrestre hoy sumergida, y que se deberia fechar en el xI milenio antes del presente. Para Hadleigh-West, el complejo de Denali tiene un paralelo en el Asia del nordeste en la cultura de Diouktaï de la cuenca del Aldan, publicada por Mochanov (1976-1977). Para nosotros esta analogía es persuasiva.

\section{DESARROLLO CULTURAL DEL NORDESTE DE ASIA ENTRE $11 / 10.000$ Y $8.000 B P$}

El cambio de las condiciones climáticas en los inicios del Holoceno en las regiones septentrionales del nordeste de Siberia consiste sobre todo en la sustitución de la tundra con escasos matorrales por una tundra salpicada de árboles. En las regiones situadas más al sur, como en las cuencas del Kolyma e Indigirka, y en Kamtchatka, se observa un desarrollo
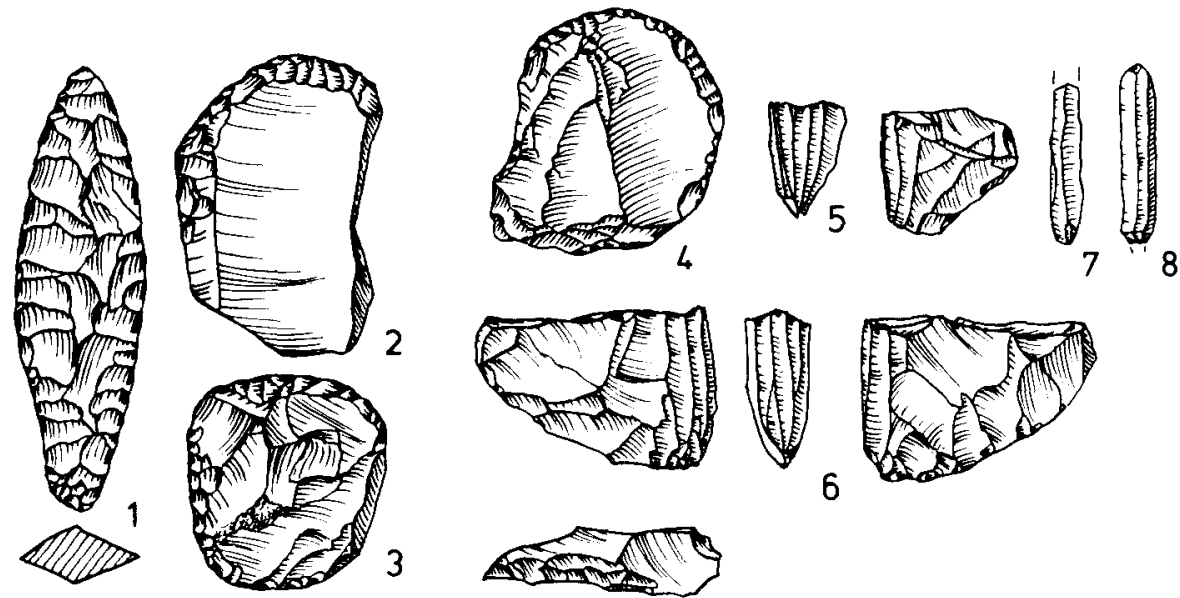

6
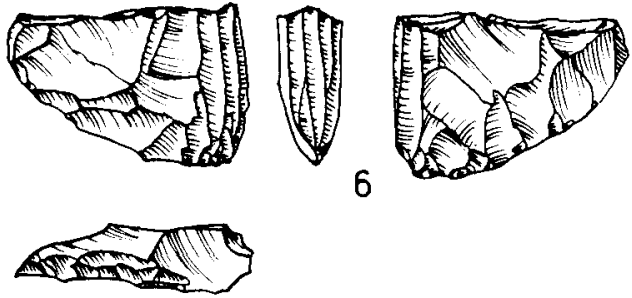

Fig. 18. Campus Site (Alaska): 1 punta foliácea, 2 a 4 raspadores, 5 y 6 núcleos de tipo Gobi, 7 y 8 hojitas (según H. G. Bandi 1969). 


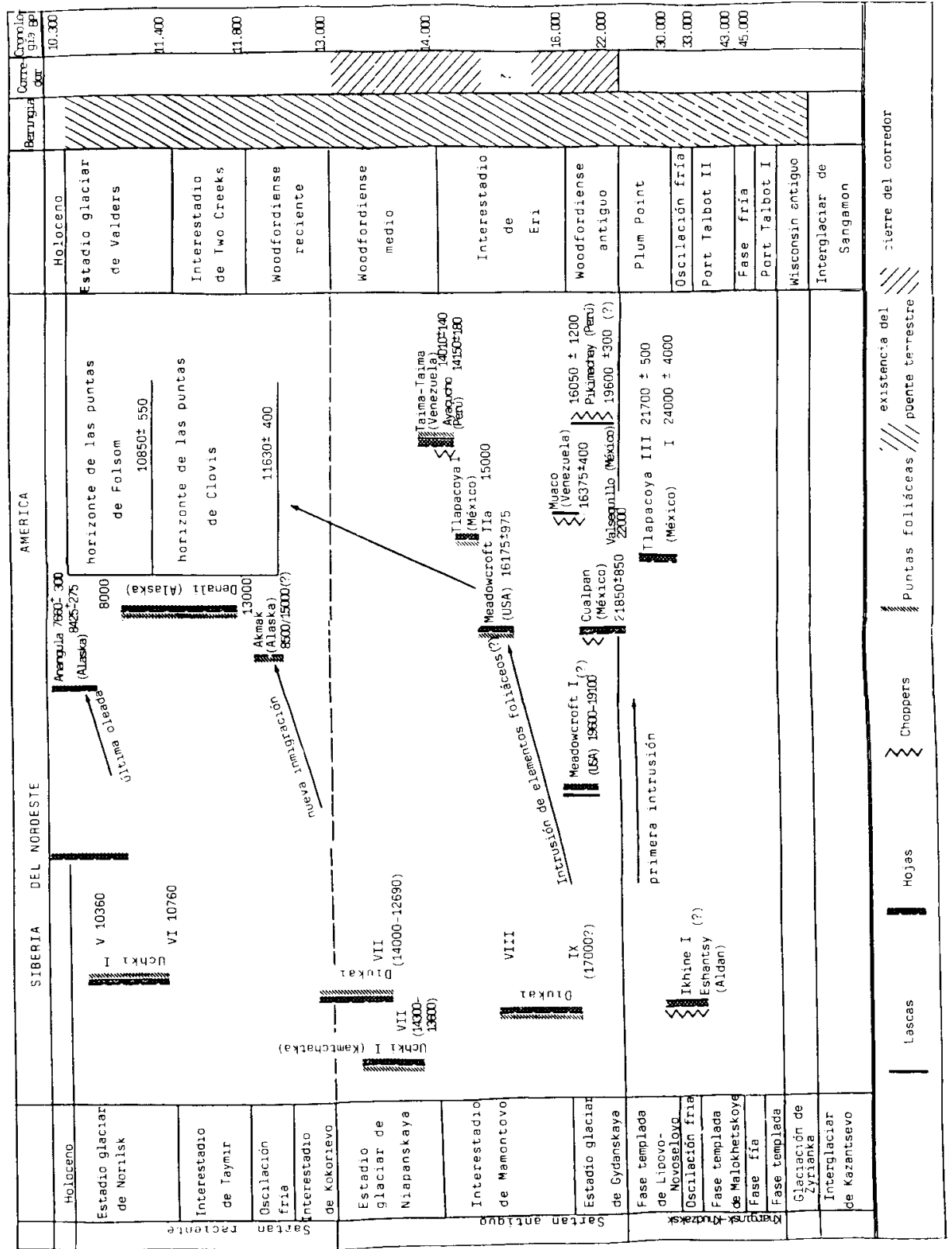


del bosques poco densos, en particular de pinos y de larix, rodeados de alisos. A este paisaje siguieron los bosques más densos en los que aparecen el abeto, el abedul y el sauce (Svvinova 1976). Pero los cambios más importantes se producen en la fauna, con la desaparición de los grandes mamíferos del Pleistoceno. Todo ello influyó mucho sobre la evolución de las culturas paleolíticas, expresándose por modificaciones en las tradiciones liticas, las de puntas foliáceas y las de choppers y hojas, al igual que por la aparición en el nordeste de Asia de nuevas tradiciones de técnica laminar.

Los complejos con puntas foliáceas persisten en Kamtchatka, donde están representados por los niveles medios del yacimiento de Ouchki 1 (niveles VI-V) fechados en 10.769-10.360 BP (Dikov 1977, 1979) (fig. 19), y del yacimiento de Ouchki $V$ (nivel Va) fechado en 8.790 BP. En todos estos conjuntos existen las hojitas obtenidas de núcleos de tipo gobiense, pero en su fase final de explotación estos núcleos se hacen más bien cónicos. Esta tendencia también se observa en los conjuntos industriales más recientes del desierto de Gobi (KozLowskı 1969). Las industrias de Kamt-
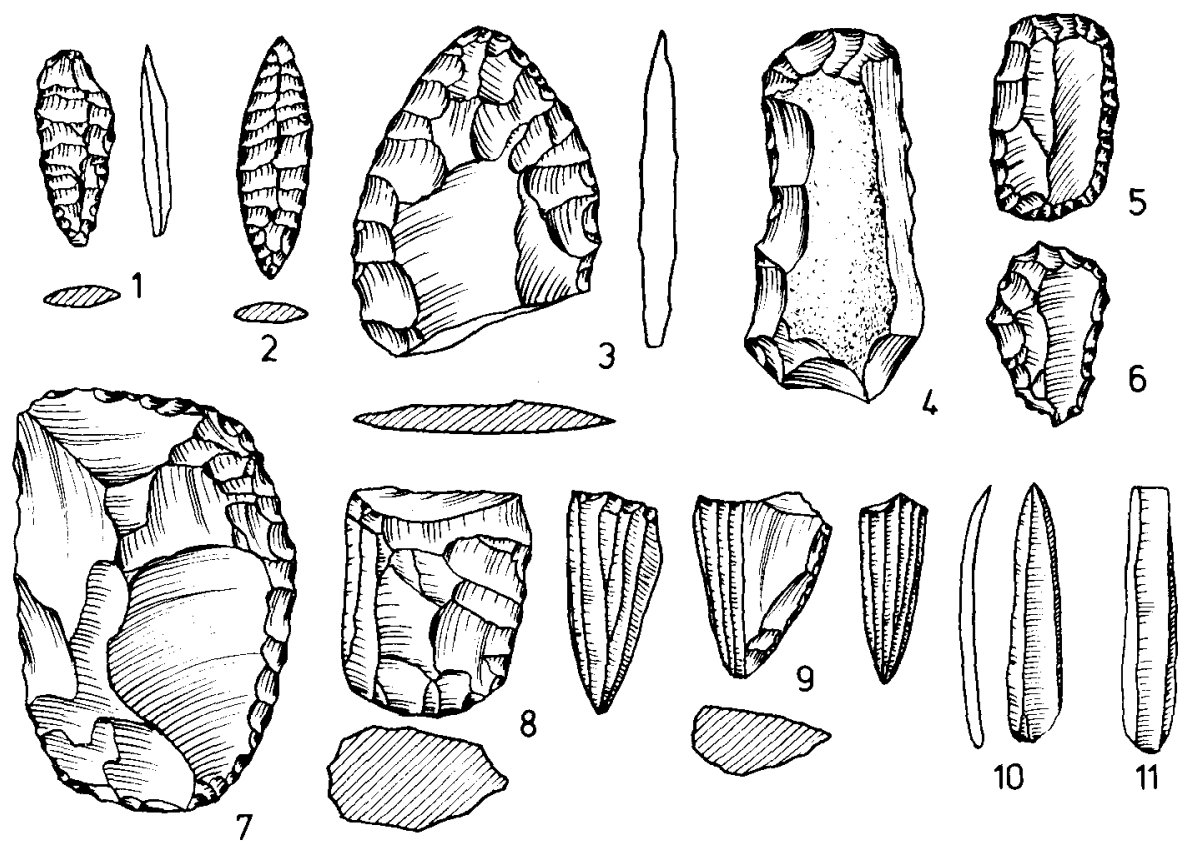

Fig. 19. Uchkil (Kamtchatka), nivel VI: 1 a 3 puntas foliáceas, 4 a 6 raspadores, 7 raedera. 8 y 9 núcleos de tipo Gobi, 10 y 11 hojitas (según N. N. Dikov 1977). 
chatka se caracterizan por los utensilios retocados, en particular raspadores sobre hoja, a veces retocadas, con frecuencia bastante cortos, pasando a los ejemplares subcirculares, y por las raederas con retoques bastante invadientes. Las puntas foliáceas siguen estando siempre presentes, pero son más bien subtriangulares, en hoja de laurel o en hoja de sauce, sin pedúnculo. Sus secciones son siempre biconvexas, simétricas.

Los utillajes de la cultura de Ouchki son bastante próximos a los de la cultura Denali en Alaska y derivan probablemente de la misma tradición. Su extensión territorial debia ser al principio bastante local, limitada al nordeste asiático, puesto que la cultura de Denali ya no tiene analogia con las industrias caracteristicas de las regiones más occidentales de Siberia. Es evidente que en las demás entidades del nordeste asiático encontramos asimismo elementos análogos a la cultura de Denali, por ejemplo en la cultura de Diouktaï y en las culturas del litoral del Pacífico (por ejemplo en los conjuntos con puntas foliáceas de Hokkaido). Nosotros no iremos por ello tan lejos como Dikov (1979) que ve en la cultura de Ouchki un prodecesor inmediato de la cultura de Denali. Más bien supondríamos la existencia de un antepasado común para las dos entidades, o bien nos permitimos sugerir que, en el estado actual del conocimiento de la prehistoria del nordeste asiático, es preferible referirse a la cultura de Diouktaï, que precede de forma suficiente en el tiempo los primeros conjuntos de tipo Denali en Alaska.

Los cambios tipológicos y tecnológicos tuvieron lugar igualmente en el marco de las tradiciones de hojas y de choppers en el nordeste de Asia. Por ejemplo podemos fechar del paso del Pleistoceno al Holoceno los utillajes de Kolyma, en particular el nivel inferior del yacimiento de Kongo, con la datación de C14 de 9.470 BP (Dıkov 1977). Este nivel está caracterizado por los choppers con un borde cortante rectilineo, y por las hojas obtenidas de núcleos cónicos. Enitre los utensilios retocados señalaremos la presencia de raspadores, buriles diedros y buriles sobre fractura. El nivel superior del mismo lugar fechado en $8.655 \mathrm{BP}$, es también rico en choppers. En la cuenca del Kolyma se conoce la misma tradición en el nivel III del yacimiento de Siberdik, con las dataciones de 8.480 y 8.020 BP, donde los choppers están acompañados de hojitas obtenidas de núcleos de tipo gobiense. Los utensilios retocados están representados sobre todo por los buriles sobre hoja rota, los raspadores, las hojitas con retoques finos a veces inversos o alternos sobre los dos bordes estrictamente paralelos (Ilamadas hojitas de Borki), y por algunas raederas bastante gruesas. Las puntas foliáceas son aqui raras, generalmente de cara plana y evocando las de las islas japonesas (Dikov 1979, fig. 32). 
Un elemento completamente nuevo está representado por las industrias laminares de la cuenca del Aldan, donde sustituyen por completo la cultura de Diouktaï (fig. 20). Estas industrias fueron agrupadas por Mochanov (1978) bajo la denominación de "cultura de Sumnagin», incluyendo Belkatchi (con su más antigua datación en $8.700 \mathrm{BP}$ ), Ust'-Timpton (niveles $\mathrm{VI}$ y IV con dataciones en 10.650 y $6.380 \mathrm{BP}$ ), y Sumnagin (donde los ni-
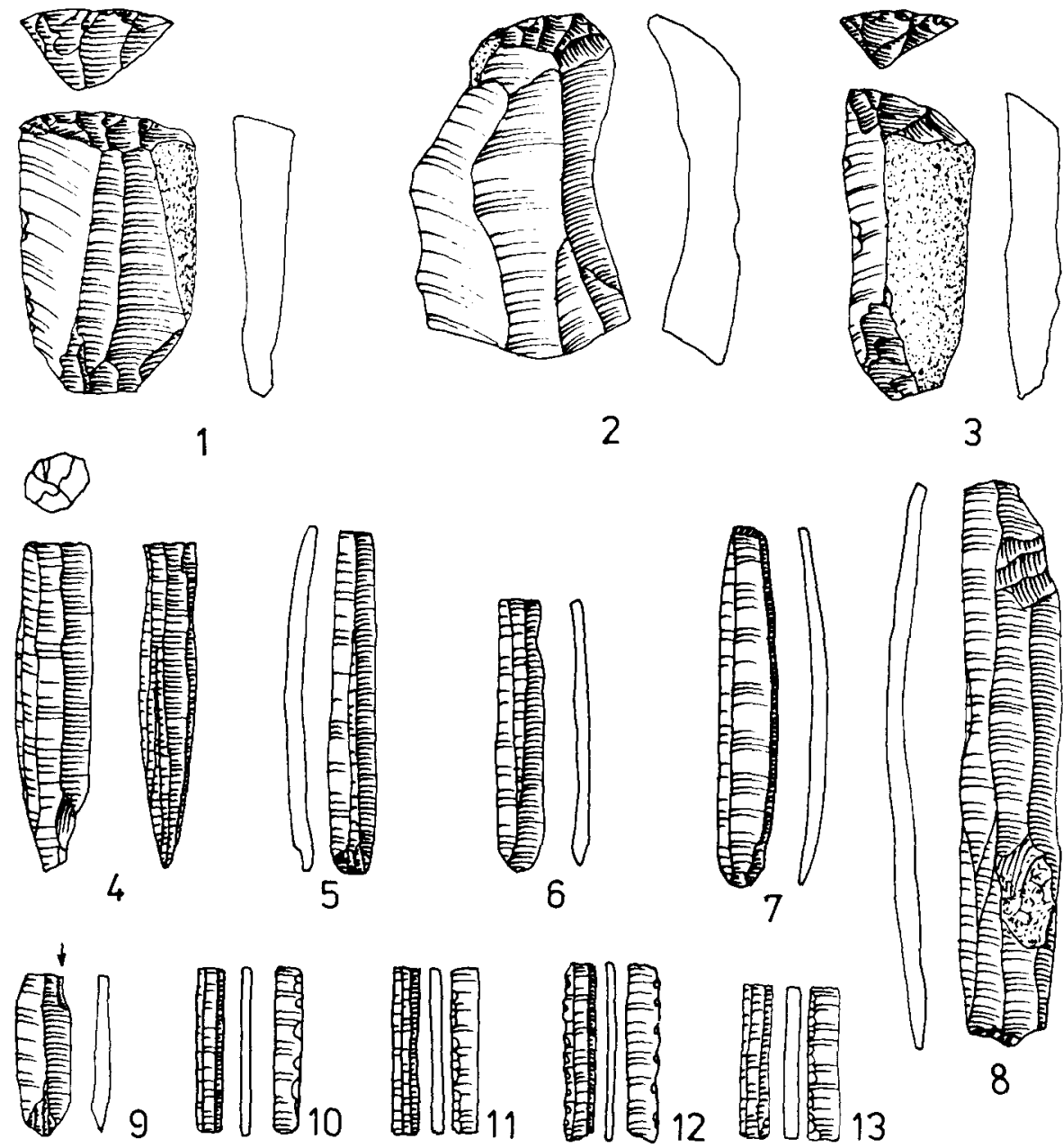

3

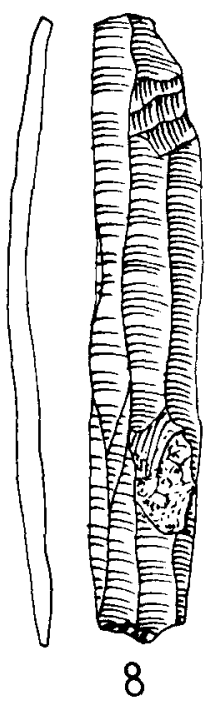

Fig. 20. Belkatchi (cuenca del Aldan), niveles XII, XIX, XXIII. Industria litica de la cultura de Sumnagin: 1 a 3 raspadores, 4 núcleo cónico, 5, 6, y 8 hojitas, 7 troncatura retocada, 9 buril microlitica, 10 a 13 hojitas de Borki (según J. A. Mochanov 1978). 
veles más antiguos - XLIV-XI - pertenecen ya a un horizonte cronológico más reciente, con la datación $6.280 \mathrm{BP}$ ).

La industria lítica de Sumnagin está caracterizada por la técnica laminar basada en un núcleo cónico con un plano de percusión. Se obtenian asi hojas finas, muy estrechas, transformadas en buriles sobre fractura (26-35\%), raspadores (18-21\%), troncaduras retocadas (5-8 \%), y perforadores $(1-2,3 \%)$. Las hojitas presentan a veces un fino retoque y representan el tipo de Borki. También hay que señalar la presencia de algunas raras piezas esquirladas (aproximadamente $1 \%$ ) y de hachas talladas bifaces, asimismo bastante raras.

Como conclusión podermos decir que, durante el paso del Pleistoceno al Holoceno, se observa en el nordeste de Asia una desaparición gradual de la tradición con puntas foliáceas y con técnica lamelar de tipo gobiense, o sea de la tradición que originó la cultura Denali en Alaska. Por el contrario, las industrias con choppers y con hojas se mantuvieron localmente preservadas. Un elemento definitivamente nuevo está representado por la cultura de Sumnagin en la cuenca del Aldan, fechada desde el XI al VII milenio BP, que podria derivar de un fondo más antiguo de las industrias laminares más occidentales, como por ejemplo las de Malta-Buret.

\section{POSIBLES INTRUSIONES EN EL NOROESTE DE AMÉRICA ENTRE $11 / 10.000$ Y $8.000 B P$}

En el epigrafe 11 se ha mencionado que el complejo de Akmak, que puede ser puesto en evidencia estratigráficamente en el noroeste de Alaska en un periodo anterior a $8.500 / 8.000 \mathrm{BP}$, no parece tener ningún parentesco con las industrias de hojas que se conocen desde hace algún tiempo de Alaska. Teniendo en cuenta sólo los más importantes hallazgos de este género, mencionaremos en primer lugar la Gallagher Flint Station, o más exactamente, la localidad 1 de este yacimiento, publicada por E. J. Dixon (1975). Está situada en la región del curso superior del rio Sagavanirtok, al norte de la Brooks Range. La localidad 1 ha sido fechada mediante el $\mathrm{C} 14$ en $10.540 \mathrm{BP}$. Su material se compone de un importante número de núcleos, por lo general destinados a la producción de hojas bastante grandes, pero no sin la presencia del tipo en forma de quilla utilizado para la fabricación de hojitas microlíticas. El número de hojas y de hojitas es considerable. Por el contrario, la falta de bifaces es absoluta. 
Intentando encontrar paralelos a este aspecto de Gallagher Flint Station, Dixon la compara a las cuevas del Trail Creek, en la peninsula de Seward, donde H. Larsen mencionó la posibilidad de la presencia de cazadores de bisontes entre 15.000 y 13.000 BP (LARSEN 1968); pero como hasta ahora no se ha encontrado ningún resto cultural de esta población, no nos parece posible el ponerla en relación con los ocupantes de la Gallagher Flint Station. La comparación que Dixon establece con el descubrimiento de W. S. Laughlin y su equipo en el islote de Anangula, cerca de la isla de Umnak, en el centro de la cadena Aleutiana (LAUGHLIN y AIGNER 1966), nos parece más importante. La existencia de una industria de hojas sin ninguna presencia de bifaces o de piezas foliáceas es evidente. Con la ayuda del C14 el lugar ha sido fechado a finales del IX milenio BP.

Hay que preguntarse pues si unas industrias como la de la localidad 1 de Gallagher Flint Station y la de Anangula no son mojones de otra inmigración que habria tenido lugar en la época de la transición del Pleistoceno al Holoceno. Como hemos visto en el epigrafe precedente, el origen de este movimiento podría encontrarse en el campo de la cultura de Sumnagin (MOCHANOv 1978). Las analogias entre esta cultura y los mencionados yacimientos de Alaska se refieren sobre todo a los utensilios retocados y a la producción de hojas aunque en Alaska, al lado de núcleos cónicos, los núcleos de tipo Gobi siguen sirviendo para la producción de hojitas. Esto si es correcta nuestra interpretación basada en las insuficientes ilustraciones de los trabajos Dixon (1975) y de Laughlin y Aigner (1966).

\section{EL DESARROLLO CULTURAL DE NORDESTE DE ASIA ENTRE 8.000 Y $6.000 B P$}

El desarrollo ulterior de las condiciones climáticas en el nordeste de Asia entre 8.000 y $6.000 \mathrm{BP}$ está caracterizado por el aumento de la vegetación del tipo de taiga boscosa, lo que está atestiguado por la mayoria de los diagramas polinicos de las cuencas de Kolyma y del Indigirka, como también por los de Kamtchatka. El limite septentrional de los bosques estaba avanzado en unos 150 a $200 \mathrm{~km}$ más al norte de los bosques actuales. Estos cambios ecológicos tuvieron mucha influencia sobre el 
proceso de adaptación de los cazadores postpaleolíticos en el nordeste asiático.

En la literatura soviética se han emitido muchas opiniones diferentes a propósito de la posición de estos grupos postpaleoliticos en el desarrollo cultural general de las sociedades prehistóricas. Asi, por ejemplo, Mochanov (1977) designa a estos grupos como epipaleolíticos o como representantes del «Paleolítico holoceno»; por el contrario, otros prefieren utilizar el nombre "Mesolitico" (Formozov 1965); e incluso algunos autores ven en estos grupos los representantes del Neolítico, ya en el vil milenio BP (Dıkov 1979). A nuestro parecer no hay ninguna razón para definir estos grupos como paleoliticos, a causa de los importantes cambios, en particular económicos y culturales, que se produjeron durante el paso entre el Pleistoceno y el Holoceno, como ya hemos subrayado en el epigrafe 12. Por otra parte, tampoco hay ninguna razón para determinar estos grupos como neolíticos a causa de la falta total de cualquier indicio de economia productiva. Incluso la introducción de la cerámica y de los utensilios de piedra pulimentada durante el vil y el vı milenio BP no son suficientes para considerar estos grupos humanos como neoliticos. En cambio parece mucho más justificado el ver en esos grupos los representantes de un sistema de adaptación postpleistocénico, que se asemeja en múltiples aspectos a los caracteres del Mesolitico europeo (dispersión de los hábitats, papel desempeñado por la caza de pequeños animales, la pesca y la recolección en la economia, importancia de las hachas talladas en el inventario lítico, etc.).

El rasgo más importante de la evolución de las culturas del nordeste asiático durante el periodo entre 8.000 y $6.000 \mathrm{BP}$ es su carácter local en los límites de las cuencas fluviales o en otras mesoregiones. Únicamente en Kamtchatka, después de la desaparición de las industrias con puntas foliáceas, existe un hiatus atestiguado por los niveles Va (8.790 BP) y IV (4.200 BP) del yacimiento del Uchki V. El último nivel está caracterizado por una industria laminar (en el que las hojas y las hojitas eran obtenidas de núcleos cónicos o cilíndricos), acompañada de hachas talladas y escasas puntas bifaciales.

En la cuenca del Kolyma la tradición local de los choppers y las hojas persiste en el horizonte en cuestión. Esta tradición se reparte en dos subtradiciones: una del tipo de Maltan con choppers típicos bastante raros, pero rica especialmente en hachas talladas (Maltan, nivel II fechado en $7490 \mathrm{BP})$, y la otra de Siberdik, rica en choppers acompañados de numerosos utensilios laminares (buriles, raspadores) y raras puntas foliáceas (Siberdik, nivel II fechado en 6.300 BP). La cerámica aparece en estas tradiciones un poco más tarde, hacia $4.500 \mathrm{BP}$. 
Es probable que la misma tradición de choppers y de hojas, con raras puntas foliáceas, existiese igualmente en el litoral del Pacifico entre Kamtchatka y Tchukotka, pero en esta región se han excavado muy poco lugares y para ninguno se posee una datación radiométrica.

Como ya hemos dichos en el epigrafe 12 , una tradición completamente diferente se desarrolla en la cuenca del Aldan, representada por la cultura de Sumnagin que evoluciona hasta $6.000 \mathrm{BP}$. La composición tipológica de los utillajes de esta cultura comprende, también en su fase reciente, los buriles, los raspadores, las hojitas con retoques finos, las truncaturas rotocadas y los perforadores, pero asimismo, como elemento nuevo, algunas puntas pedunculadas con retoque plano en la base, que evocan las puntas de Swidry. La presencia de estas puntas, asi como la de hojitas Borki, es un fenómeno muy extendido en el Holoceno antiguo a través de toda Siberia hasta la Europa oriental, pasando por el Ural.

El territorio de la cultura de Sumnagin, al igual que las cuencas del Aldan y del Lena, fueron invadidos hacia el $6.000 \mathrm{BP}$ por las nuevas entidades culturales caracterizadas por las hachas talladas pulimentadas, los arpones en hueso y la cerámica. Estas entidades culturales parecen derivar de la región de Transbaikalia y de la cuenca del Angara.

Durante el estadio siguiente del desarrollo se observa la formación de zonas culturales más bien longitudinales, o sea la cultura del Lena medio en la parte meridional de la Siberia oriental, las culturas del Lena inferior, del litoral del mar de Okhostk y de Tarin en la parte centro-oriental de Siberia, y finalmente las culturas de Tchukotka y de Ust-Belskaya en el extremo nordeste de Siberia.

\section{EL DESARROLLO EN ALASKA DURANTE EL HOLOCENO}

Es indudable que la tradición de Denali -que, según $\mathrm{F}$. Hadleigh-West, seria la rama oriental de una Beringia Tradition - tuvo una gran influencia sobre el desarrollo cultural sucesivo en Alaska y en otras regiones de la zona ártica y subártica de América. Al parecer, los portadores de esta cultura, que eran aún cazadores de animales terrestres, avanzaron con bastante rapidez en diferentes direcciones adaptándose, al mismo tiempo y en las regiones litorales, a la caza de los mamiferos acuáticos: nos encontramos en el nacimiento de la cultura esquimal.

En Alaska, los mojones importantes de este desarrollo son los más antiguos hallazgos de las cuevas del Trail Creek, al norte de la península de Seward, que H. Larsen fecha en un periodo en torno al 8.000 BP (LAR- 
SEN 1968) y el Denbigh Flint Complex descubierto por J. L. Giddings en Cape Denbigh, Norton Sound (GidDIngs 1964). Esta última industria, que después ha sido identificada en muchos otros lugares de Alaska, data de mediados del IV milenio BP. Su material lítico está caracterizado especialmente por artefactos microliticos obtenidos a partir de núcleos cilindricos (la técnica de núcleos de Gobi falta en absoluto); en lugar destacado, hay que mencionar las puntas y las armaduras (en forma de medias-lunas y triángulos) cuidadosamente retocadas por las dos caras, con frecuencia en diagonal. Un segundo elemento importante son unas puntas que recuerdan las paleo-indias, en particular por su forma y sus retoques bifaciales, $y$ en algunos casos también por un acanalado. El tercer elemento caracteristico de la industria lítica de Denbigh son los buriles: tanto verdaderos buriles correspondientes a los del Paleolítico superior del Viejo Mundo, como pseudo-buriles, trabajados sobre pequeños bifaces, lo que tiene como resultado que los golpes de buril no han producido una arista sino una especie de punta. En el yacimiento de lyatayet, en el Cap Denbigh, los objetos en materia ósea no se han conservado; pero la estratigrafía de las cuevas del Trail Creek demuestra que las puntas en asta de reno con ranuras laterales probablemente formaban parte de la misma (LARSEN 1968).

Aunque es evidente que el Denbigh Flint Complex, que algunos autores incluyen en la denominación Artic small tool tradition, deriva del Denali Complex, parece probable que otras influencias contribuyeron a su formación. Uno se siente tentado de tomar en consideración lo que D. D. Anderson denomina la Northern Archaic Tradition (ANDERSON 1968), es decir las tradiciones paleo-indias que llegaban al norte, después de que el corredor en la barrera de hielo hubiese permitido a los animales y a sus cazadores el retroceder desde las regiones meridionales de América del Norte hacia el 15.000 BP. Es menos probable que la tradición de las industrias de hojas, como ya hemos mencionado sobre todo en Anangula, hubiese contribuido también a la formación de la cultura de Denbigh. Podria ser que la continuación de esta tradición esté restringida al callejón que forman las islas Aleutianas. El Denbigh Flint Complex desempeñó muy probablemente un papel importante en el desarrollo de culturas como las de Choris y la de Norton en las que el carácter esquimal se hace evidente.

\section{CONCLUSIONES}

En este estudio hemos querido demostrar como el Asia del noroeste y América experimentaron durante la última glaciación un desarrollo cul- 
tural que tomó una dirección autónoma a partir del Paleolitico superior, independiente del resto del Viejo Mundo.

1. Este despliegue empieza en principio en el nordeste de Asia en el periodo inter-pleni-glaciar de Kharginsk-Khudzaksk, dado que la existencia de industrias más antiguas en esta zona, sugerida por Okladnikov y Vasilevski (1980), no está suficientemente probada por hallazgos indiscutibles. Por el contrario, los más antiguos utillajes bien documentados se fechan en el periodo evocado y están representados en el nordesde de Siberia por las industrias con choppers y con hojas y en el sudeste de Siberia por las industrias de técnica levalloisiense y laminar, en ocasiones también acompañadas por choppers. Del comienzo del periodo de Sartan datan las culturas de tipo Paleolitico superior de Afontova Gora a orillas del Yenisei y de Malta-Bouret' en las del Angara. Todas estas industrias no conocian todavia las puntas foliáceas.

2. Por tanto no es sorprendente que los primeros hallazgos en América no sean mucho más antiguos y se fechen hacia $22.000 \mathrm{BP}$, es decir del periodo inmediatamente precedente al comienzo del Woodfordiense antiguo. Desde el punto de vista tecnológico estos hallazgos representan una sintesis de tres elementos: choppers, hojas y lascas. La extrema rareza y pobreza de las más antiguas industrias indiscutibles de América, hacen difícil la comparación más detallada con los posibles antecedentes asiáticos, aunque encontremos las mismas tradiciones tecnológicas en el Asia oriental. Por tanto debe admitirse que el hombre del Paleolítico superior asiático utilizaba el puente terrestre de Beringia hacia el final del periodo Kharginsk-Khudzaksk, o sea en el momento de la máxima recesión del mar. Los desplazamientos de los grupos humanos desde Alaska hacia el sur de América debieron tener lugar antes de la clausura del corredor continental por la máxima extensión de los glaciares de la época del Woodfordiense antiguo (aproximadamente 22.000 BP).

3. El cierre del corredor continental por la extensión de los glaciares, a pesar de la existencia del puente terrestre de Beringia, cortó los contactos entre Asia y América por lo menos entre 20.000 y 16.000 BP. Durante este periodo, las industrias de América sufrieron un desarrollo local hasta ahora poco conocido, aunque los efectos de esta evolución se conocieran más tarde bajo la forma de unas industrias que derivaban del fondo común con choppers, lascas y hojas. En cambio en Asia, en el mismo periodo, aparecen elementos nuevos, en particular bajo la forma de puntas foliáceas, cuyo 
origen ampliamente discutido en nuestro estudio, es probablemente halógeno. Estas puntas aparecen entre 17.000 y 13.000 en los utillajes de la cuenca del Aldan, en las regiones en torno al lago Baikal, en la costa del Pacífico y en el Japón. Tanto su morfología como su contexto lítico están bastante diferenciados.

4. Las primeras puntas foliáceas aparecen en América casi en el mismo periodo que en el Asia oriental, o sea entre 16.000 y 13.000 BP. Aunque estas puntas estén presentes en el contexto que sería más bien local, nos parece que no derivan del mismo, como supone A. Bryan. Más bien habria que contar con la posibilidad de una nueva oleada llegada de Asia a través de Beringia, que habria atravesado el corredor continental en el momento mismo de su reapertura hacia el 16.000 o el $15.000 \mathrm{BP}$, en el interestadio de Eri.

5. El desarrollo ulterior de las puntas foliáceas en América es sin duda local, sobre todo para la formación de las puntas con acanalado de tipo Clovis. No se encuentra ninguna correspondencia directa para estas puntas en Asia oriental. Con la retirada de los hielos, hay que tener en cuenta la posibilidad de migraciones en el sentido opuesto, desde el sur hacia el norte de América, tanto en lo que se refiere a las industrias de puntas con acanalado como las que derivan del fondo más antiguo "pre-foliáceo".

6. Al propio tiempo, en Asia casi todas las tradiciones locales se desarrollan hasta el final del Pleistoceno sin cambios esenciales, aunque ciertas tradiciones se cruzaron dando lugar a nuevas culturas como las de Kokorievo y de Selenga.

7. Una nueva oleada de población del Asia oriental aparece en Alaska hacia 13.000/12.000 BP. Está representada por una industria con utensilios foliáceos bifaces, hojas y lascas, y con hojitas obtenidas a partir de núcleos del tipo Gobi, distinguida generalmente bajo la denominación de complejos de Akmak y de Denali o American paleoartic tradition. Esta industria debió tener antecedentes asiáticos en la cultura de Diouktai, si bien algunas afinidades persisten en el periodo más tardio con la fase reciente de la cultura de Ouchki. No puede aceptarse una migración inversa para explicar estas afinidades, como propone N. Dikov.

8. La última oleada llegada desde Asia a América está representada por las industrias esencialmente laminares del tipo GallagherAnangula en Alaska, que probablemente deben estar en relación con la cultura de Sumnagin en la cuenca del Aldan. Esta migración tuvo lugar hacia $10.000 \mathrm{BP}$, poco antes de la interrupción del puente terrestre de Beringia. La repartición territorial de estas indus- 
trias demuestra que quedaron limitadas principalmente al litoral de Alaska.

9. Después de la ruptura del puente terrestre de Beringia, durante la mayor parte del Holoceno, no se observan contactos entre los dos continentes. En el Asia del nordeste, los cambios importantes en la cultura material tuvieron lugar con el proceso de adaptación de los cazadores paleoliticos a las condiciones ecológicas del Holoceno. Por el contrario, en el noroeste de América prosigue su desarrollo la tradición de Denali que, con la interferencia de otras tradiciones procedentes del sur, está en el origen de la cultura esquimal.

\section{BIBLIOGRAFIA}

Abramova, Z. A. (1970): "Paleolit youjnoi Sibiri" (Paleolitico de la Siberia meridional), en Sibir $i$ ee sosedi $v$ drevnosti. Novosibirsk.

- (1978): "Paleolititchecskoie poselenie Krasny Jar na Angarie» (Yacimiento paleolitico de Krany Jar en el Angara), en Drevniye kuoltouri Priangaria. Novosibirsk.

- (1979): Paleolit Yeniseya (Paleolitico del Yenisei). Moscú.

- (1980): K voprosu o vozrastie aldanskogo paleolita (La cuestión de la edad del Paleolitico del Aldan). Sovietskaya Arkheologuia, vol. 4.

Aovasio, R. et al. (1978): Meadowcroft Rockshelter. Early man in America. Edmonton.

Ameghino, F. (1906): Les formations sédimentaires du Crétacé supérieur et du Tertiaire de Patagonie. Anales del Museo Nacional. Buenos Aires, 14.

Anderson, D. D. (1968): "A Stone Age Campsite at the Gateway to America" Scientific American, vol. $218, \mathrm{n}{ }^{\circ} 6$, págs. $24-33$

- (1970): "Akmak. An Early archeological assemblage from Onion Portage, NW Alaska", Acta Arctica. Copenhague, fasc. XVI.

ANokovirch, M. V. (1976): "Nekotoryie itogi raskopok Atchinskoy paleolititcheskoi stoyanki" (Algunos resultados de las excavaciones en el yacimiento paleolitico de Atchinskaya), en Sibir centralnaya $i$ vostochnaya Azia $v$ drevnosti. Novosibirsk.

BANDI, H. G. (1964): Eskimo Prehistory. Londres.

BANDI, H. G. (1977): “Die Rentierfolgetheorie - Eine Hypothese des 19. Jahrhunderts über die Herfunft der Eskimos aus Westeuropa und ihre heutique Beurteilung", Bericht der Römisch-Germanischen Kommission, 58.

BONNICHSEN, R. (1978): "Critical arguments for pleistocene artifacts from the Old Crow Basin, Yukon. A preliminary statement", Early Man in America. Edmonton.

Borden, C. E. (1965): "Radiocarbon and geological dating of the Lower Frazer Canyon sequence", Proceedings of the 6th International Conference on Radiocarbon and Tritium Dating. Pullman.

- (1975): Origins and development of early north-west coast culture to about $3000 \mathrm{BC}$. Ottawa.

BosCh-GIMPERA, P. (1962): "Die ersten Besiedelungswelten auf dem amerikanischen Kontinent», Saeculum, t. 13, n. ${ }^{\circ}$ 2, págs. 121-131

Bryan, A. (1973): "Paleoenvironments and cultural diversity in the Late Pleistocene of South America", Quaternary Research, fasc. 3.

- (1978): Early Man in America from a circum-Pacific perspective. Edmonton 
Canals Frau, S. (1953): Préhistoire de l'Amérique. Paris.

Cruxent, J. (1956): "A lithic industry of Paleo-Indian type in Venezuela". American Antiquity, vol. 22, fasc. 2 .

- (1961): «Huesos quemados en el yacimiento prehistórico de Muaco». Departamento de Antropologia de IVIC, Boletin Informativo. Caracas.

- (1967): El Pelo-Indio en Taima-taima. Acta Cientifica Venezolana, supl. vol. 3

DawkINS, B. (1866): “Esquimaux in the South of Gaul». The Saturday Review, 8-12-1866. Londres.

- (1874): Cave Hunting. Londres.

Derevianko, A. P. (1969): "Paleolit Dalniego Vostoka" (El Paleolítico del Extremo Oriente), en Istoria, Arkhoeloguia i Etnografia Dalniego Vostoka. Vladivostok.

- (1978): "The problem of the Lower Palaeolithic in the south of the Soviet Far East". Early Paleolithic in South and Bast Asia. La Haya.

Dıkov, N. N. (1977): Arkheologitcheskiye pamiatniki Kamtchatki, Tchoukotki i Verkhney Kolimi (Yacimientos arqueológicos del Kamtchatka, Tchukota y del Kolima superior). Moscú

- (1979): Drevniye koultouroi Severo Vostotchnoy Azii (Las antiguas culturas del nordeste de Asia). Moscú.

Dixon, E. J. (1975): "The Galagher Flint Station. An Early Man Site on the North Slope of Arctic Canada and its Role in Relation to the Bering Land Bridge", Arctic Anthropology vol. XII, n. ${ }^{\circ} 1$.

Formazov, A. A. (1965): "O terminie mezolit i yego ekvivalentakh" (Sobre la expresión Mesolitico y sus equivalentes). Sovietskaya Arkheologuia, fasc. 3.

GidoIngs, J. L. (1964): The Archaeology of Cape Denbigh. Providence.

Guidon, N. Y ARNAUD, B. (1991): "The chronology of the New World: Two faces of one reality", World Archaeology, vol. 23, 2.

Greenman, E. F. (1963): "The Upper-Palaeolithic and the New World", Current Anthropology, vol. $4, n{ }^{\circ} 1$, págs. 41-91.

HADLEIGH-WEST, F. (1967): "The Donnely Ridge site and the definition of an early cave and blade complex in central Alaska”, American Antiquity, vol. 32, n. ${ }^{\circ} 3$, págs. 360-382.

- (en prensa), The Archaeology of Beringia.

HOPKINS, D. M. (ed.) (1967): The Bering Land Bridge. Stanford.

HoRgan, J. (1992): "Early arrivals", Scientifique American, feb. 1992.

HrdlickA, A. (1923): "The Origin and Antiquity of American Indian", Annual Report Smithsonian Institution, págs. 481-494.

IRVING, W. N. (1968): "Upper Pleistocene Archaeology in Old Crow Flats". Arctic Circular, vol. 17 , fasc. 2.

- (1971): "Recent Early Man Research in the North», Arctic Anthropology, vol. 8, fasc. 2.

IRVING, W. N., et al. (1986): "Indications of Pre-Sangamon Humans near Old Crow, Yukon, Canada", en New Evidence for the Pleistocene Peopling of the Americas, Orono.

IRWIN-WILLIAMS, C. (1967): "Association of early man with horse, camel and mastodon at Hueyatluco", en P. S. Martin y H. E. Wright (ed.), Pleistocene extinctions. New Haven.

IVANOVA, I. K. (1980): "Geologitcheskiye uslovia nakhojdenia paleolita na territorii SSSR" (Las condiciones geológicas del Paleolitico de la URSS), Biuleten Moskovskogo Obchtchestva Ispitateley Prirody, vol. 19, fasc. 3.

JiA, L. (1980): Early Man in China. Beijing.

KonStANTINOV, M. V. (1980): “Koultourno-istoritcheskiye etapy istorii yougo-zapada Zabaikalia” (Las etapas culturales e históricas del desarrollo de Zabaikalia del sudoeste), Arkheologitcheskii Poist-Severnaya Azia. Novosibirsk.

Kontrimavichus, V. L. (ed.) (1976): Beringia in Cenozoic. Vladivostok.

KozLowSKI, J. K. (1969): “Problem kultury Shabarak usi i niektore sporne zagadnienia paleolitu potudniowej Mongolii» (El problema de la cultura Shabarak-usu y la discusión en torno al Paleolitico de la Mongolia meridional), Przeglad Archeologiczny, vol. 18.

- (1970): "The problem of the so-called Ordos Culture in the light of the paleolithic finds from Northern China and Southern Mongolia», Folia Quaternaria, vol. 40. 
Krieger, A. D. (1964): "Early Man in the New World", Prehistoric Man in the New World. Chicago.

LARITCHEV, V. P. (1964): «Moustierskiye i neolititcheskiye pamiatniki youjnoj Gobi» (Los yacimientos musterienses y neoliticos de Gobi del sur), en Arkheologia i Etnografia Dalniego Vostoka. Novosibirsk.

- (1976): "Paleolit Mandjourii, Vnoutriennoy Mongolii i Vostochnogo Turkestana" (EI Paleolitico de Manchuria, Mongolia y Turkestan), en Sibir, Centralnaya i Vostochnaya Azya $\checkmark$ drevnosti. Novosibirsk.

LARSEN, H. (1968): "Trail Creek", Acta Arctica (Copenhague), fasc. XIV.

LAUGHLIN, W. S. y Aigner, J. S. (1966): "Preliminary Analysis of the Anangula Unifacial Core and Blade Industry", Arctic Anthropology, vol. Ill, n. ${ }^{\circ}$ 2, págs. 41-56

Lerol-Gourhan. A. (1965): Préhistoire de l'art occidental. Paris.

LYNCH, T. F. (1974): "The Antiquity of Man in South America", Quaternary Research, vol. 4, facs. 3.

LoRENZO, J. L. (1978): “Early Man Research in the American hemisphere: appraisal and perspectives", Early Man in America. Edmonton.

MAC NEISH, R. S. et al. (1970): Second Annual Report of the Ayacucho archeological-botanical project. Andover.

- (1971): “Early Man in the Andes», Scientific American, n. ${ }^{\circ} 224$, fasc. 4

Medoev, A. G. (1972): "Radialnaya sistema izgotovlenia noukleousov Levallois $v$ drevniem paleolite Sary Arka i Mangyshlaka» (El sistema de preparación radial de los núcleos Levallois en el paleolitico antiguo de Sary Arka y de Mangyshlak), en Poiski i raskopki $\checkmark$ Kazakhstane. Alma-Ata.

Mendes Correa, A. A. (1928): “Nouvelle hypothèse sur le peuplement primitif de l'Amérique du Sud", Ann. Fac. Sc. do Porto, vol. 15, págs. 5-31.

Mirambel, L. (1978): "Tlapacoy: a late Pleistocene site in Central Mexico". Early Man in America. Edmonton.

Mochanov, J. A. (1976): "Paleolit Sibiri", en Beringia $v$ Kainzoie. Vladivostok

- (1977): Drevnieychiyie etapy zaselenia chelovekom Severo-Vostochnoy Azii (Las más antiguas etapas del poblamiento del Asia del nordeste). Novosibirsk.

- (1978): "The Palaeolithic of North-East Asia and the problem of first peopling of America", Early Man in America. Edmonton.

Morlan, J. V. (1971): "The preceramic period in Japan", Arctic Anthropology, vol. 8, fasc. 1

MulleR-BECK, H. J. (1966): "Jäger- und Sammlerkulturen Nord-asiens und Amerikas", en Narr, K. J. (ed.), Handbuch der Urgeschichte, t. I. Berna y Munich.

- (1979): "Paleohunters in American: origin and diffusion", Science, vol. 112, n." 3.276.

- (1979): «Zur Archaeologie der amerikanischen Arktis”, Beiträge zur allegemeinen und vergleichenden Archeologie, t. 1.

OKLADNIKov, A. P. (1959): "Paleolit Zabaikala» (Paleolitico de Zabaikalia), Arkheologuitcheski Sbornik, vol. 1, Ulan-Oude.

- (1962): «Issledovaniya kamennogo veka v Mongolii» (Investigaciones sobre la Edad de la Piedra en Mongolia), Sovietskaya Etnografia, fasc. 1.

- (1978): "The Paleolithic of Mongolia", en Ikawa-Smith, F. (ed.), Early Palaeolithic in South and East Asia. La Haya.

Okladnikov, A. P. y Vasilevskiy, R. S. (1980): Severnaya Azia na zarie istorii (El norte de Asia en los albores de la historia). Novosibirsk.

OrR, P. C. (1968): Prehistory of Santa Rosa island. Santa Bárbara

PAGE, W. L. (1978): "The geology of the El-Bosque Archaeological site, Nicaragua», Early Man in America. Edmonton.

Powers, W. R. (1973): “Palaeolithic Man in Northeastern Asia», Arctic Anthropology, vol. 10, fasc. 2.

ROUdENko, S. J. (1960): "Ust Kanskaya pechtcheranaya paleoliticheskaya stoyanka" (La cueva de Ust-Kanskaya - yacimiento paleolitico). Paleolit i Neolit SSSR, vol 4.

Rouse, I. (1976): «Peopling of the Americas», Quaternary Research, vol. 6. 
SANFORD, J. T. (1971): “Sheguiandah reviewed", Anthropological Journal of Canada, vol. 9 , fasc. 1.

Savvinova, G. M. (1976): "Rastitelnost verkhovev rek Indigirki i Kolymi v pleistocenovyie-golotsenovoyie vremia" (La vegetación en los cursos superiores del Kolyma y del Indigirka en la época del Pleistoceno-Holoceno). Beringia v Kainozoie. Vladivostok.

SMITH, Ph. (1962): "A fluted point from the Old Wordl", American Antiquity, vol. 28, fasc. 2.

SOLECKI, R. S. (1951): "Archaeology and Ecology of the Arctic Slope of Alaska". Smithsonian Report for 1950, págs. 469-495.

STALKER, A. y MAC, S., "Indications of Wisconsin and earlier man from the southwest Canadanian prairies", en Amerinds and their paleoenvironmens in North-eastern North America. New York Academy of Sciences, annals, vol. 288.

SzABo, B. J. et al. (1978): "Dilemma posed by uranium series dates on archaeology significant bones from Valsequillo, Puebla, México", Earth and Planetary Science letters, vol. 6. fasc. 4.

TomskaYA, A. J. y SAVVINOVA, G. M. (1975): “Sporovo-pylsevoye spektry olojenii doliny Aldana" (Los diagramas polínicos del valle del Aldan), en Yakoutia $i$ ee sosedi $v$ drevnosti. Yakutsk.

TSEITLIN, S. M. (1972): «Nekotoryie voprosy geologiii i geologitcheskoy periodyzacjipamitan।kov paleolita Sibiriin (Algunos problemas de la geologia y de la periodización geológica de los yacimientos paleoliticos de Siberia), Biuleten Komisji po Izoutcheniou Tchetvertichnogo Perioda, fasc. 38.

VANCE HaYnes, C. (1971): "Time environment and Early Man", Arctic Anthropology, vol. 8, fasc. 2.

VASILEVSKI, R. S. (1979): "Dokeramitcheskiye kompleksy Sakhalina i ich korelaja s pamiatnikami sosednikh oblastiey" (Los yacimientos precerámicos de Skhalin y su correlación con los territorios vecinos), en Drevniye koultouri Sibirii Tikhookeanskogo Baseyna. Novosibirsk.

WILLEY, G. (1971): Introduction to American Archaeology; vols. I y II. Englewood Cliffs.

NOTA DEL TRADUCTOR.-Queremos dar las gracias a nuestros colegas y amigos los profesores Dr. Janusz K. Kozlowski (Universidad de Cracovia) y Dr. Hans-Georg Bandi (Swis-Lichtlustein Foundation for Archaeological Research Abroad, Vaduz) por haber amablemente accedido a que tradujeramos al castellano su estudio «Le problème des racines asiatiques du premier peuplement de l'Amérique» que fue originalmente publicado en el Bulletin de la Société suisse des Américanistes (t. 45, 1981, págs. 7-42, 19 figs.), sumándole, además, algunas notas complementarias para ponerlo al dia.

Aunque sin la amplia presencia que merece la compleja arqueología de la América prehispánica, no se puede decir que ésta haya estado ausente de las páginas de EFT en su breve existencia. Precisamente en un articulo del profesor Juan Schobinger titulado: «200.000 años del hombre en América: ¿qué pensar?» (serie I, Prehistoria y Arqueologia, t. I, 1988, págs. 375-395) se planteaban como en el presente, los arduos problemas que suscitan las cada vez más antiguas dataciones que atestiguan la primera presencia del hombre en América.

Para que el lector conociera otro enfoque del tema hemos tenido empeño en publicar este trabajo de los profesores Kozlowski y Bandi que 
intenta sistematizar y razonar las teorias tradicionales, pero aportando también sus muchos conocimientos sobre las tierras que se extienden a ambos lados del mar de Beringia. Recordaremos que el profesor Kozlowski es un gran conocedor de las civilizaciones paleolíticas del Asia oriental, amén de ser un gran especialista de las edades líticas centroeuropeas (por ej.: "The Gravettian in Central and Eastern Europe», $A d$ vances in World Archaeology, t. 5, 1986, págs. 131-200), mientras que el profesor Bandi, entre muchas otras cosas, es un gran conocedor de las culturas esquimales (cf. por ej.: Urgeschichte der Eskimo, Stuttgart, G. Fischer, 1964, traducido al inglés con el titulo Eskimo Prehistory. The University of Alaska Press, s. a. -1968?-, o Alaska, Urgeschichte, Geschichte, Gegenwart. Stuttgart, Kohlhammer, 1967). Uno de los méritos notables de su estudio es el utilizar y aportar una bibliografia especializada que muchas veces escapa al lector de lengua castellana, a causa del idioma que contiene la información, caso del ruso, o por tratarse de libros y revistas de carácter muy especializado, caso de los investigadores norteamericanos de su propia Prehistoria, cuyas producciones, en ambas ocasiones, tan escasamente llegan a nuestras bibliotecas. También lo es por la estrecha correlación que procura establecer entre los fenómenos geológicos y las industrias liticas y óseas. Para los testimonios arqueológicos el lector debe tener en cuenta que se está tratando de cazadores primitivos con una gran movilidad, en territorios ampliamente sometidos a las oscilaciones glaciales, formados por grupos pequeños en número $y$, por tanto, habiendo dejado restos arqueológicos bastante escasos.

Acaso en esta ocasión también convenga recordar el voluminoso "estado de la cuestión" (hasta 1950 aproximadamente) que escribió el profesor Luis Pericot Garcia, América indigena, t. I, El hombre americano, Los pueblos de América. Barcelona, Salvat, ${ }^{2} 1961$, en particular los capítulos II («El problema del hombre cuaternario en América», págs. 221-422) y III («El problema del origen del hombre americano», págs. 423-574), con aportación de una gran cantidad de bibliografia agudamente comentada.

Si algún error hubiera en el texto que antecede deberia achacarse a la traducción que ha realizado directamente el firmante. La intervención en el mismo se ha procurado que fuera minima, limitándose a la ocasional adaptación del fr. ou por el cast. $u$, o a la de algún topónimo general.

Este del primer poblamiento americano es un tema que incluso llega a interesar al hombre de la calle. Va avanzando en su esclarecimiento un selecto y disperso grupo de investigadores que trabajan en universidades y centros científicos para poner luz en el enigma. Desgraciadamente la investigación española poco ha contribuido a estos estudios, pues, por lo general —con muy escasas excepciones- no ha habido en las autori- 
dades de nuestro pais durante el siglo $x x$ ningún interés en promocionar aqui y allá el estudio del pasado americano prehispánico. Para aseverarlo basta tan solo con repasar la bibliografia especializada y constatar en ella la escasez, cuando no la ausencia total, de autores españoles. Algún nombre señero, un muy pequeño número de trabajos puntuales y alguna obra de sintesis, son la excepción a esta regla. Incluso, en tiempos bien recientes, quedó injustamente truncado por responsables de la conmemoración colombina, el proyecto - realizado en cuatro anualidades sucesivas - de traer a nuestro pais y de forma sistemática las mejores muestras de la arqueología prehispánica y a sus principales estudiosos, por áreas geográfico-culturales.

Al lado de las de hombres de ciencia norteamericanos son importantes las aportaciones al tema de los origenes americanos las de un buen número de especialistas hispano-americanos. $Y$ tambièn hay que señalar, como ocurre con el trabajo que motiva estas lineas, las valiosas contribuciones de hombres de ciencia de diversos paises europeos con deuda mucho menor que los españoles con el mundo americano.

En todo caso, la versión castellana de este trabajo se incorpora a la literatura científica de los origenes del hombre en América en la oportunidad de conmemorarse en el presente año el $V$ Centenario de una efemérides que en el estricto sentido de la palabra bien podria calificarse de trascendental "redescubrimiento».-E. RIPOLL PERELLO. 